\title{
Grain Boundaries and Diffusion Phenomena in Severely Deformed Materials
}

\author{
Gerhard Wilde* and Sergiy Divinski \\ Institute of Materials Physics, University of Münster, Wilhelm-Klemm-Str. 10, 48149 Münster, Germany
}

The present knowledge on grain boundary-related phenomena specific for severely plastically deformed materials is reviewed and critically analyzed in detail. Severe plastic deformation is shown to introduce specific metastable states of the grain boundaries which are characterized by enhanced diffusion rates, high-density of specific structure elements and large (still localized) elastic strains. An intrinsic heterogeneity of the deformation-induced modifications is revealed and examined on different scales. Relations between the existence of deformation-modified grain boundaries, specific microstructure features and resulting properties are highlighted. [doi:10.2320/matertrans.MF201934]

(Received February 27, 2019; Accepted April 12, 2019; Published June 25, 2019)

Keywords: severe plastic deformation, grain boundary, diffusion, point defects, dislocations, HPT, ECAP

\section{Introduction}

Bulk ultrafine grained or nanostructured materials obtained through Severe Plastic Deformation (SPD) raised much interest due to the potential to adjust the grain size of massive materials over large ranges, reaching the submicron - or even the nanometer scale. ${ }^{1,2)}$ Related to the adjustment of SPDachieved ultrafine grained (UFG) microstructures and also related to the specific processing pathways, unusual and highly beneficial properties and property combinations such as highly enhanced strength at a still good ductility, and even improved functional properties have been reported. ${ }^{3,4)}$

At the outset of the current interest in SPD-achieved ultrafine grained materials, the authors of the first experimental results in this field suggested that - concomitant to grain refinement - the atomic structure of grain boundaries (GBs) is modified by the severe deformation processing, too. 5) A theoretical model for the modified grain boundary structures based on the absorption of lattice dislocations has been proposed, ${ }^{6}$ and the resulting high-angle grain boundaries with additional excess free energy density have been termed 'non-equilibrium' grain boundaries. According to earlier works, ${ }^{5,6)}$ these 'non-equilibrium' grain boundaries should be responsible for the enhanced mechanical properties of materials processed by severe plastic deformation that exceed the property advances which are expected just on the basis of grain size changes alone. Since all grain boundaries in a single-component material represent non-equilibrium defects, this nomenclature is not fully appropriate, ${ }^{7)}$ and these grain boundaries with enhanced excess energy densities ${ }^{8,9)}$ are better to be referred as 'grain boundaries in a deformation-modified metastable state' or 'deformationmodified grain boundaries' (DMGBs). We thus would like to note at this point that we are using that term to strongly distinguish SPD-induced and SPD-influenced metastable high-angle grain boundaries with random misorientation and enhanced excess free energy, enhanced excess free volume and enhanced microstrain, from relaxed high-angle grain boundaries (HAGBs) of the same (non-special) misorientation - even induced via SPD processing - as they could be found in well-annealed coarse-grained polycrystal-

*Corresponding author, E-mail: gwilde@wwu.de line materials. The existence of a certain fraction of DMGBs after SPD processing has recently been proven, mainly by research work of the authors of this overview. ${ }^{9-12)}$ Furthermore, there is experimental evidence that SPD processing might produce specific grain boundary states which might either limit ductility because of internal stresses ${ }^{13)}$ or improve ductility because of stress-aided static recovery. ${ }^{14-16)}$ While creep in SPD-processed materials is probably the most intensively studied issue, ${ }^{10,17)}$ a direct relation between the appearance of DMGBs and affected creep properties is still unclear. ${ }^{18)}$ Yet, that might be related to the fact that considerable relaxation might occur before/ when creep conditions are reached. Additionally, diffusion as well as transmission electron microscopy measurements ${ }^{9)}$ have shown that only a fraction (of about 10-20\%) of the high angle grain boundaries are in the state of DMGB after severe plastic deformation. Thus, while forming a percolating network for fast grain boundary diffusion, that fraction might be too small for promoting considerable creep. One of the main conclusions which is to be drawn from the existing knowledge is that grain boundary diffusion is a most appropriate tool for revealing the deformation-modified state of interfaces, since grain boundary contrast as revealed solely by TEM could be insufficient or even misleading. ${ }^{7,8)}$

Although a large amount of data on the microstructure evolution and partially also on the related mechanical properties of a wide range of severely deformed metals and alloys have become available, ${ }^{2,19)}$ the impact of the SPDspecific grain boundary modification on the mechanical performance is still controversial and a matter of dispute. The relation between processing conditions and microstructure evolution for different materials has not been clarified either, and different materials properties have been suggested as controlling parameters. Rather recently, the stacking fault energy has been suggested as a key parameter controlling microstructure evolution as well as the resulting mechanical performance of SPD-processed materials. ${ }^{2)}$ Unfortunately, concerning a concise approach towards related SPD processing, microstructure development and resulting property modification, the large number of empirical data is matched by only a few systematic studies that allow in-depth comparisons of different properties of the starting material or of different processing routes concerning the behavior 
during SPD and the resulting (mechanical) properties after SPD, see e.g. Ref. 20). In fact, due to variations of the purity of the starting material or due to variations of the processing pathway in the work published in the literature, it is still rather difficult to identify a consistent dataset that spans some range of microstructures or processing parameters even for pure materials such as $\mathrm{Cu}$, which is one of the moststudied materials in this context. On the other hand, it is clear from hitherto literature that, e.g., different impurity levels at the ppm scale, different processing routes with different hydrostatic pressure components and/or with different intermediate treatments, etc. can - for a given material have a dramatic impact on e.g. the finally attainable grain size, the level of internal stresses, or the development of porosity, i.e. on achieved strength and ductility. ${ }^{21,22)}$ Thus, quantifying the impact of the individual contributions of different SPD conditions or materials properties, such as the stacking fault energy on the microstructures and the related properties of the ultrafine grained or nanocrystalline materials is still a challenging task. ${ }^{23)}$

Additionally, there have been many discussions in the literature recently on the importance of twinning ${ }^{24,25)}$ and stress-driven grain boundary migration ${ }^{26}$ ) as two alternative mechanisms for stress accommodation in ultrafine grainedand nanocrystalline materials, i.e. in situations where the conventional dislocation-based plasticity is near to exhaustion. ${ }^{27)}$ These two mechanisms are strongly dependent on the stacking fault energy of the material as well as on the strain field at grain boundaries. Twin formation by emission of partial dislocations from the grain boundaries has been shown in computer simulations to be of importance at small grain sizes and high strain rates, which are accessible for atomistic simulations. ${ }^{28)}$ At the same time, specifically the formation of twin boundaries presents the basic and necessary ingredient of so-called "grain boundary engineering", 29,30) which has been shown to lead to stabilized microstructures with enhanced mechanical performance.

Thus, conceptually, SPD-processing down to ultrafine grain sizes coupled to thermal treatment (at very high defect densities, "annealing" at room temperature or continued deformation might be equivalent to thermal annealing of conventionally processed materials) might naturally lead to microstructures that present similar features as grain boundary engineered materials. Thus, in order to address the impact of the DMGBs on the mechanical properties of ultrafine grained materials obtained by severe plastic deformation, analyses of the microstructure on different length scales including the atomic structure and the residual strain of the near-grain boundary regions should be coupled to measurements of the macroscopic mechanical properties of the same materials while varying their stacking fault energy in a controlled way.

The present review summarizes the recent results of the authors on kinetic, thermodynamic and structural properties of internal interfaces in SPD-processed materials and their impact on the microstructure evolution. Recent findings are presented with respect to the relationship between processing conditions, intrinsic materials properties (specifically of the stacking fault energy) and the materials response to severe plastic deformation as well as the resulting microstructures and related mechanical properties after severe plastic deformation with structural and kinetic properties of the interfaces in SPD-processed materials.

\section{Interfaces under Straining}

Severe plastic deformation, as already indicated by the term itself, serves to create a rather "exotic" state of materials concerning defect densities, phase compositions or generally concerning all aspects of microstructure. In terms of a wellknown energy-landscape approach, SPD, as a process, leads to a drastic increase of the generalized potential energy of the deformed materials due to the storage of excessive amounts of excess energy that has been transferred to the material as mechanical work under conditions where the rate of excess energy storage exceeded the rate of excess energy annihilation. Thus, after processing and without additional mechanisms that promote fast relaxation of this "excited" state of matter - given by the condition that the room temperature corresponds to a relatively homologous temperature with respect to the melting point of the material, the generalized potential energy of the severely deformed material is above all relatively deep local minima. Such a condition offers the potential for exploring a wider range of the phase space, since otherwise existing kinetic limitations do not apply. For this reason, severe plastic deformation has been applied to obtain a starting state as well as an initiation process for subsequent microstructure evolution and specifically for adjusting microstructures and structures and distributions of internal interfaces that are known to enhance material's performance for conventional, often coarse-grained materials. This approach was chosen in order to analyze if those existing concepts can be adopted for UFG materials or if the SPD-induced state might even improve the microstructure response. Specifically, "grain boundary engineering" according to the concept presented by Watanabe $^{31)}$ and, in a separate investigation the combination of different strengthening and toughening mechanisms, not only related to internal interfaces, have been investigated for SPD-processed alloys. These two topics will be shortly discussed in the following.

\subsection{Grain boundary engineering of severely deformed alloys?}

With alloys in contrast to pure elements, specifically for solid solution-forming systems, parameters such as e.g. the stacking fault energy or the homologous temperature of the material can be systematically varied. In addition, processes such as e.g. solution strengthening, dispersion strengthening or microstructure stabilization via grain boundary pinning or GB segregation are only possible if more than one elemental component is present. For analyzing the impact of an SPDinduced UFG microstructure on the propensity for grain boundary engineering and, at the same time, for analyzing the dependence of the microstructure response to SPD as function of materials parameters (such as e.g. the stacking fault energy), the completely miscible alloy system $\mathrm{Cu}-\mathrm{Ni}$ has been chosen. ${ }^{32}$ ) The phase diagram of $\mathrm{Cu}-\mathrm{Ni}$ shows a simple lense-type topology where the melting temperature decreases for increasing $\mathrm{Cu}$ content. A miscibility gap at 


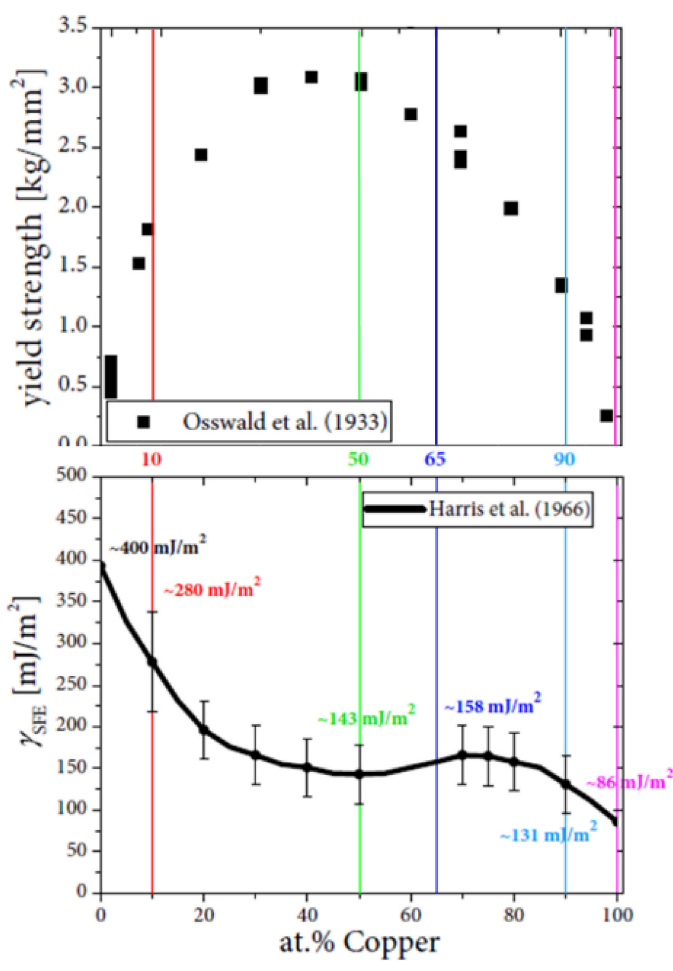

Fig. 1 (upper panel) Composition dependence of the yield strength as a measure for solid solution effects after Osswald et al. ${ }^{35)}$ The maximum is shifted to lower $\mathrm{Cu}$ values of approximately 40 at\%. (lower panel) Theoretical values of $\gamma_{\mathrm{SFE}}$ of the $\mathrm{Cu}-\mathrm{Ni}$ system from Ref. 37). The investigated compositions and their corresponding $\gamma_{\mathrm{SFE}}$ are marked. Near the equiatomic composition a local minimum of $\gamma_{\mathrm{SFE}}$ is expected.

lower temperature for higher $\mathrm{Ni}$ content, predicted for the equilibrium state by thermodynamic modeling ${ }^{33)}$ and observed recently in nano-layered films, ${ }^{34)}$ does not affect the results of the present study due to kinetic reasons.

$\mathrm{Cu}$ and $\mathrm{Ni}$ form a substitutional solid solution. The solid solution effects can reliably be estimated on the basis of the composition dependence of the yield strength in nonprecipitating and non-segregating alloy and the $\mathrm{Cu}-\mathrm{Ni}$ system seems to represent a suitable choice. Osswald investigated the yield strength for specifically orientated crystals in different monocrystalline $\mathrm{Cu}-\mathrm{Ni}$ alloys, ${ }^{35)}$ plotted in Fig. 1. There is an increase in the solid solution effect up to approximately $40 \mathrm{at} \%$ of $\mathrm{Cu}$ followed by a decrease. ${ }^{35,36)}$

For the $\mathrm{Cu}-\mathrm{Ni}$ system, Harris et al. used a texture method based on the dependence of cross-slip on $\gamma_{\mathrm{SFE}}$ for an estimation of the $\gamma_{\mathrm{SFE}}$ value. ${ }^{37)}$ The stacking fault energies obtained by these estimations are shown in Fig. 1 , too. $\gamma_{\mathrm{SFE}}$ decreases for higher $\mathrm{Cu}$ contents. The decrease is pronounced from $0 \%$ to $40 \%$, and from $90 \%$ to $100 \%$ of $\mathrm{Cu}$. $\gamma_{\mathrm{SFE}}$ has a rather constant value between $40 \%$ and $90 \%$ of $\mathrm{Cu}$ with a local minimum close to the equiatomic composition.

The systematic variation of the composition within the $\mathrm{Cu}-\mathrm{Ni}$ system from pure $\mathrm{Cu}$ to pure $\mathrm{Ni}$ enabled discussing the microstructure development and microstructure stability as well as the hardness of the respective material in dependence of $\gamma_{\mathrm{SFE}}$, the solid solution effect and the homologous deformation/annealing temperatures, respectively, for SPD-processed and for SPD plus annealing treated states. ${ }^{32)}$ In addition, utilizing a tailor-made software tool for analyzing grain boundaries as well as triple junctions (see below), the abundance of special low- $\Sigma$ GBs and special triple junctions, as required by grain boundary engineering, were also quantitatively determined. ${ }^{32}$ )

Thus, it was found that the different materials parameters, such as the stacking fault energy, the homologous temperature for processing or post-deformation annealing and the solid solution effect affect the microstructure and the related properties in different ways, which calls for a careful selection of alloy composition and processing parameters in order to achieve a material with optimum microstructure and properties through thermomechanical processing involving SPD.

If, e.g. a microstructure with small average grain size and low propensity for grain growth is desired, then an alloy composition with a strong solid solution effect should be chosen. However, an alloy composition with a low stacking fault energy needs to be chosen for maximizing the number density of special low- $\Sigma$ grain boundaries. If, on the other hand, the amount of special GBs, specifically $\Sigma 3$ and $\Sigma 9$ GBs, should be maximized in relation to the respective grain size, then again the composition should be chosen such that the solid solution effect is maximal. ${ }^{32)}$ It was found that a maximum value of the length fraction $\lambda_{\Sigma 3}$ of $\Sigma 3$-GBs of approximately $\lambda_{\Sigma 3} \approx 40 \%$ can be reached.

Thus, for successful grain boundary engineering of UFG materials in non-segregating systems, the following factors are found to be most important:

- A strong solid solution effect, leading to high thermal stability and a high fraction of $\Sigma 3-G B s$ and narrows the grain size distribution.

- A low $\gamma_{\mathrm{SFE}}$ enhances twinning and serves to achieve a high fraction of $\Sigma 9-G B s$ as well as a microstructure completely consisting of twin-related domains (TRDs).

- A high melting temperature, to achieve small grains and a high thermal stability in terms of absolute temperatures.

In Ref. 32), a microstructure consisting of a narrow distribution of small grain sizes (up to $1000 \mathrm{~nm}$ ) with a high fraction of $\Sigma 3^{\mathrm{n}}$-GBs, using one cycle of deformation and subsequent annealing was produced for the $\mathrm{Cu}_{50} \mathrm{Ni}_{50}$ and $\mathrm{Cu}_{65} \mathrm{Ni}_{35}$ alloys. However, the distribution of stabilizing elements of the microstructure is superior in the annealed $\mathrm{Cu}_{65} \mathrm{Ni}_{35}$ alloy (Fig. 2). ${ }^{38)}$ Here, in addition to grain-based aspects of the microstructure, such as the grain size or the grain orientation as well as their distributions, also the grin boundary character with respect to special low- $\Sigma$ CSL-grain boundaries and their conjunctions have been analyzed. With this analysis, at the same time, also the triple junctions as well as their nature were determined. ${ }^{39)}$ For this reason, a specially designed software tool, "pythorient" 40 ) has been created that determines triple junction maps and that is available as freeware.

As indicated by the combination of thermal stability and strength, grain boundary engineering has served to substantially improve the properties of the alloy after initial severe plastic deformation. This result indicates the potential for thermo-mechanical processing and grain boundary engineering after initial severe plastic deformation treatment. 


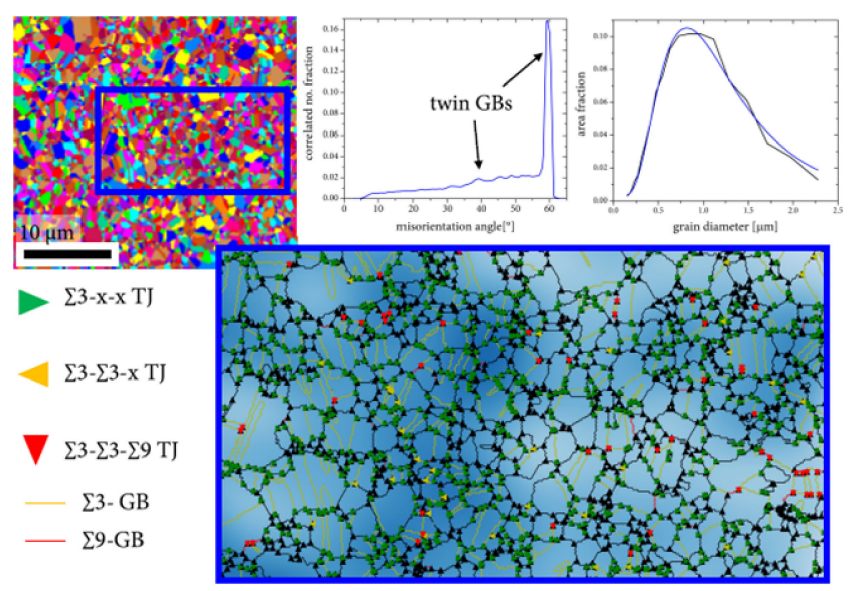

Fig. 2 Successfully GB engineered microstructure: ${ }^{32,38)}$ Cu65Ni35 annealed at $798 \mathrm{~K}$ for $30 \mathrm{~min}$. Top left: autograin-map. Top centre: misorientation distribution chart, where the related peaks to twin GBs are marked. Top right: grain size distribution chart showing a narrow grain size distribution and a log-normal tendency (fitted). Bottom: triple junction-map with marked special grain boundaries and triple junctions for a section of the whole scan area, indicated as a blue rectangle in the autograin-map. The shading of the triple junction-map is related to the density of $\Sigma 3$-x-x TJs.

\subsection{Toughening and strengthening of UFG materials}

As indicated already, UFG material after SPD processing contains high densities of defects such as vacancies, dislocations and internal interfaces, rendering them strong and usually brittle. Thus, different thermo-mechanical processing strategies were followed to obtain materials with enhanced strength and useful elongation to failure. Based on our investigations by radiotracer diffusion and transmission electron microscopy, we expect that severe plastic deformation introduces a hierarchy of heterogeneities on different length scales and concerning different aspects of microstructure: one example is indicated by the observation of "fast" and "ultrafast" diffusion pathways, see section 3. Yet, the distribution of lattice defects or, partially coupled to the resulting strain fields, the distribution of supersaturation are expected to be distributed heterogeneously, too. Thus, when post-processing as e.g. by thermal annealing is applied after severe deformation, specific attention needs to be paid concerning the existing hierarchy of kinetics (particularly of the internal interfaces). On the other hand, that hierarchy offers a new setscrew for tuning the microstructure and its distributions.

Concerning any thermal treatments after SPD processing, one needs to take into account that in addition to relaxation, recovery and grain growth that need to be minimized in order to retain the UFG microstructure, and in addition to obvious and direct consequences resulting from defect-defect interactions, such as grain boundary strengthening, the highly strained state also affects the thermochemical equilibrium of UFG alloys, as e.g. shown by enhanced solubility ranges or different phases that are preferentially formed under high strain and high-pressure conditions. Thus, any annealing procedure must be designed under the specific boundary conditions that take the deformation-induced state into account.
Additionally, it seems conceptually clear that one could also expect the solubility to vary with the defect density, a correlation which is applicable for equilibrium conditions, too. ${ }^{41)}$ Thus, creating hierarchic spatial distributions of defect densities with heterogeneous distributions might serve as a way to achieve conditions for different solute contents in different regions that could result, during a subsequent heat treatment, in spatial arrangements of precipitates having similar effects as bimodal grain size distributions. In fact, through the interactions between precipitates and grain boundaries, even both aspects could theoretically be obtained simultaneously: bimodal grain size distributions with an additional bi-modality concerning precipitate density (and/or precipitate size), yielding an effectively multi-modal microstructure.

It should be noted at this point that a short term annealing/ ageing treatment is needed to recover the ductility following SPD processing. The question is, whether it is possible to retain the strength of UFG alloys while the ductility is being recovered. For retaining strength, the recovery/grain growth/ precipitate coarsening reactions have to be controlled.

In order to test this approach and its possible validity also under realistic processing conditions, a $\mathrm{Cu}-3$ at\% $\mathrm{Ag}$ alloy was selected, ${ }^{42}$ ) which is a precipitation hardened material due to the very limited solubility of $\mathrm{Ag}$ in $\mathrm{Cu}$ at room temperature (RT). Additionally, this alloy has medium stacking fault energy, therefore twin formation is expected during both deformation and annealing. After homogenization and quenching, the precipitate-free alloy was severely deformed by cold rolling at either RT or under cryogenic conditions (at liquid $\mathrm{N}_{2}$ temperature, LNT) followed by short time annealing to introduce fine deformation/annealing twins and precipitates in the microstructure. X-ray line profile analysis and high resolution scanning electron microscopy indicate the presence of local regions of varying $\mathrm{Ag}$ content in the deformed material.

Following annealing, one could identify distinct regions with and without Ag precipitates (marked as regions 1 and 2 in Fig. 3, respectively) and the precipitates in region 1 are

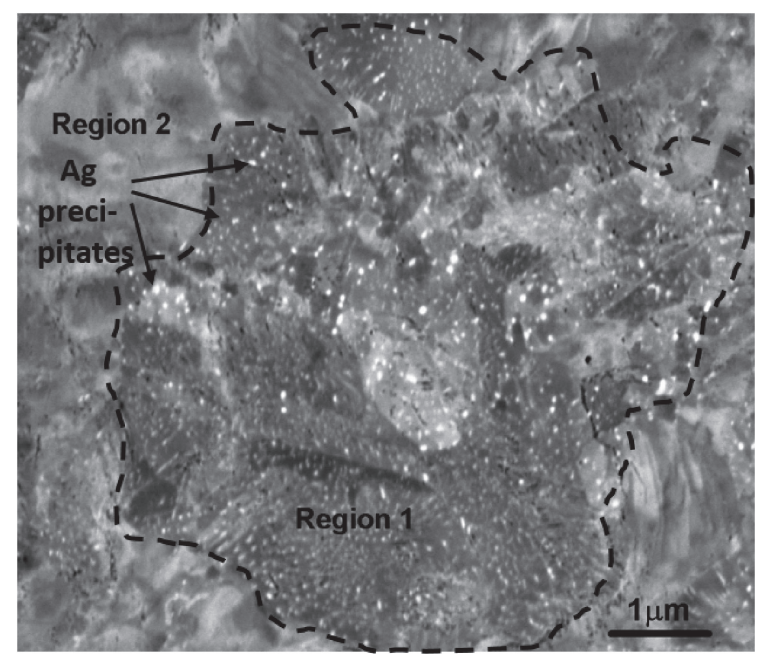

Fig. 3 Backscatter SEM image of a $\mathrm{Cu}-3$ at\% Ag alloy in LNT rolled and annealed condition. The regions 1 and 2 with different solute content in the $\mathrm{Cu}$ matrix are indicated. Arrows mark some Ag precipitates and the dashed line indicates the border between region 1 and region 2 . 


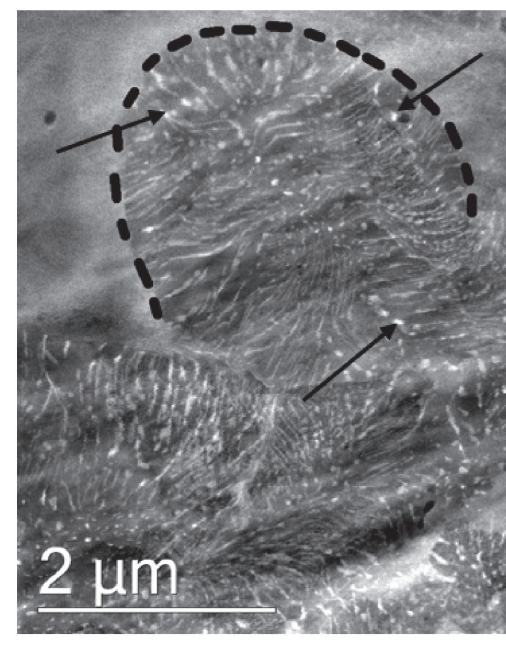

deformed \& annealed

deformed $\quad$ Cu crystallites in region 2

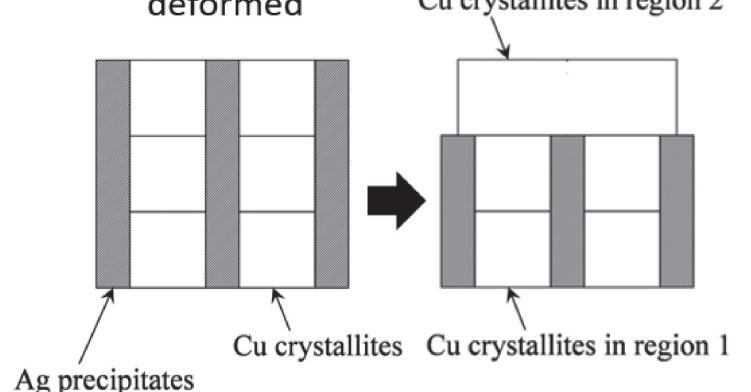

Ag precipitates

Fig. 4 High angle annular dark field (HAADF) TEM image of $\mathrm{Cu}-3$ at\% $\mathrm{Ag}$ in RT rolled and annealed condition showing discontinuous $\mathrm{Ag}$ precipitates. The precipitation is outlined with dashed lines, arrows mark the position of some precipitates. (lower) Schematic of the discontinuous dissolution process during the migration of the precipitation reaction front.

predominantly spherical with a size between $20-30 \mathrm{~nm}$. Similar regions were also observed in RT rolled and annealed sample. Discontinuous precipitates with lamellar morphology were found predominantly at random high angle grain boundaries due to the faster Ag diffusion along these boundaries. ${ }^{43-45)}$ This effect might be even more enhanced for the SPD-processed material, due to the possible formation of < grain boundaries with enhanced diffusivity along the GB plane. The high angle annular dark field (HAADF) image in Fig. 4 shows discontinuous precipitates (appearing in bright contrast) in some regions of the RT rolled and annealed sample and the white halo around the volume containing discontinuous precipitates (marked by the dotted line in the upper left corner of Fig. 4(upper)) indicates a large $\mathrm{Ag}$ solute content in the $\mathrm{Cu}$ matrix (corresponding to region 2), which was most probably formed by migration of the precipitation reaction front (i.e. discontinuous dissolution; see Fig. 4(lower) for a schematic representation).

In summary, a successful approach was demonstrated for retaining high strength while recovering ductility in a $\mathrm{Cu}-$ 3 at\% Ag alloy via cold rolling at room and cryogenic temperatures and short-time annealing just below the recrystallization temperature. In regions with higher solute (Ag) content, the high dislocation density introduced during rolling is stabilized, while in other volumes the dislocation

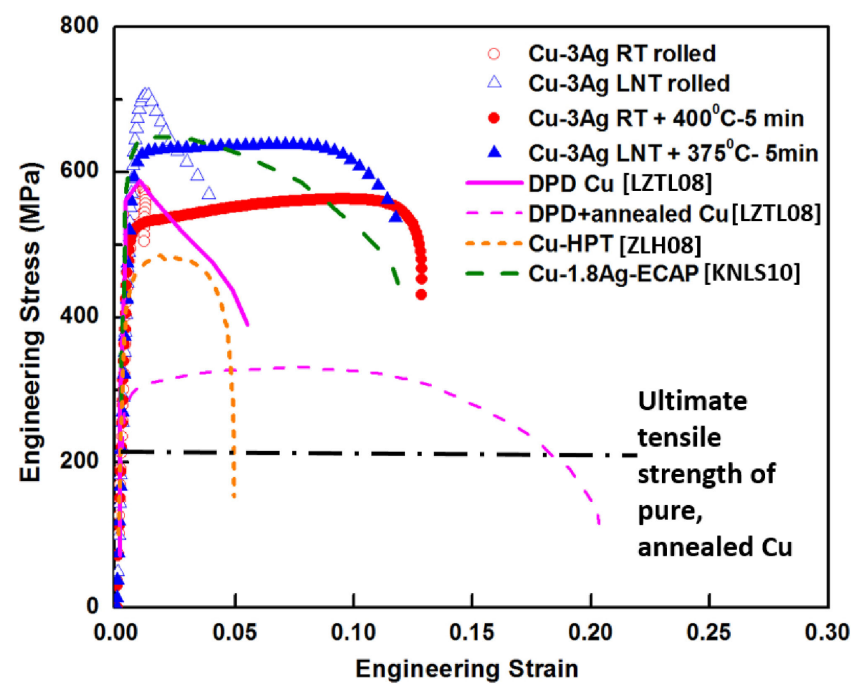

Fig. 5 Engineering stress-strain curves for RT and LNT rolled as well as the annealed $\mathrm{Cu}-3$ at\% Ag alloys. Stress-strain data taken from the literature for DPD $\mathrm{Cu},{ }^{46)} \mathrm{DPD}$ and annealed $\mathrm{Cu},{ }^{46)}$ HPT-processed $\mathrm{Cu},{ }^{47)}$ ECAPprocessed $\mathrm{Cu}-1.8$ at\% $\mathrm{Ag}$ alloy ${ }^{48)}$ are also included for comparison.

density is decreased. Microstructure analysis of the rolled and annealed samples revealed bimodal grain size -, dislocation density - and solute (Ag) distributions as well as nanosized $\mathrm{Ag}$ precipitates. The as-rolled samples exhibit high tensile strengths of $\sim 600-700 \mathrm{MPa}$ with almost negligible uniform elongation $(\sim 1 \%)$. After short time annealing, the strength decreases slightly (to $\sim 550-620 \mathrm{MPa}$ ) but is accompanied by a significant improvement in uniform elongation (from 1 up to $10 \%$ ), which is mainly attributed to the multi-bimodal microstructure.

Figure 5 shows the comparison of the stress-strain behavior of the present $\mathrm{Cu}-\mathrm{Ag}$ alloys with previously published data on $\mathrm{Cu}$ and $\mathrm{Cu}$-alloys processed by SPD methods. From Fig. 5 it is clear that RT/LNT rolled and annealed $\mathrm{Cu}-\mathrm{Ag}$ alloys exhibit the best combination of strength and ductility. This is mainly due to the development of a multi-bimodal microstructure during annealing of SPD processed $\mathrm{Cu}-\mathrm{Ag}$ alloys.

\subsection{Alloy phases far from equilibrium}

As shortly mentioned above, severe plastic deformation can also be applied to create phase compositions that are metastable or unstable with respect to the equilibrium phase diagram, e.g. solid solutions with high solute content in systems that are immiscible according to their bulk equilibrium thermodynamics. In comparison to ball milling, where high strain rates, local impact strengths, material transfer under impact conditions and also abrasive wear of the balls and the bearing unavoidably need to be taken into account, high pressure torsion serves to induce strain-induced mixing under much more controlled conditions. It is an especially suitable feature of SPD processing that the temperature of the material during severe deformation can be controlled and can be kept close to ambient, while in ball milling, high temperature excursions at impact are inherent to the process. Such high temperatures unavoidably result in relaxation processes and render the analysis of purely straindriven mixing processes difficult. 
Conceptually, SPD-processing could lead to very high supersaturation, since mixing is forced at very low homologous temperatures. Additionally, at somewhat higher temperatures, if applied after SPD processing, or after extended storage times, the fast transport along deformation-modified grain boundaries might efficiently distribute a fraction of the excess solute in the highly defected grains such that the resulting segregation of solute at the grain boundaries effectively limits the mobility of grain boundaries in directions perpendicular to the grain boundary plane. Thus, one could expect SPD-induced mixing of immiscible alloy systems to form solid solution phases with high solute content, high defect densities, resulting high hardness and high strength and high thermal stability.

In order to test these expectations and also in order to analyze the limits of shear-induced mixing at low homologous temperatures, the immiscible alloy system $\mathrm{Cu}-$ Ta was selected. ${ }^{49)}$ Experimentally, discs (diameter of $10 \mathrm{~mm}$ ) with a total sample thickness of about $1 \mathrm{~mm}$ were constructed from $\mathrm{Cu}(99.999$ mass $\%)$ and Ta $(99.99$ mass \%) foils that were cleaned and stacked to obtain a nominal composition of $\mathrm{Cu}_{50} \mathrm{Ta}_{50}$ (at\%). The stacks were subjected to HPT at $4 \mathrm{GPa}$ for $\mathrm{N}=10,30,50,100$ and 150 revolutions at $1.5 \mathrm{rpm}$. The effective applied shear strain $\gamma$ is estimated as $\gamma=2 \pi N r / \sqrt{ } 3 h,{ }^{50)}$ with the number of rotations, $N$, the sample radius, $r$, and the sample thickness, $h$. The following theoretical shear strain values, calculated with accounting for the sample thickness after HPT, were achieved: 201, 640, 1133, 2418 and 3886 at the sample edge for 10, 30, 50, 100 and 150 revolutions, respectively. These values are used here only as a reference for the maximum shear strain value. Potential deviations of strain hardening from power law behavior due to strain localization, especially during the later deformation stages, were not taken into account, since the custom-built HPT device did not allow recording the torque value.

After 150 rotations a dense, bulk nanostructured material is observed that shows chemical homogeneity on a scale of several micrometers, but significant microstructure heterogeneity on the same scale, Fig. 6. In fact, a mixture of FCC and BCC phases is detected. EDX analyses revealed that a remarkably high solid solubility of $\mathrm{Ta}$ in $\mathrm{Cu}$ has been achieved during HPT deformation. Both, Ta dissolution in the nano-sized $\mathrm{Cu}$ grains and Ta particles inside of $\mathrm{Cu}$ grains have been identified, Fig. 7. Cu dissolution in Ta nano-grains cannot be excluded due to slight variations of the XRD-peak positions. While the diffraction maxima of $\mathrm{Ta}$ also after deformation correspond to the Bragg positions observed on annealed and undeformed pure Ta, the XRD-peaks of $\mathrm{Cu}$ in the deformed material are systematically shifted towards lower angles, indicating a dissolution of $\mathrm{Ta}$ into the $\mathrm{Cu}$ grains. Applying Vegard's law ${ }^{51)}$ as a first approximation, the amount of $\mathrm{Ta}$ in the $\mathrm{Cu}$-based solid solution was estimated as 16 at\% (about 36 mass\%). This value is much larger than the literature values obtained for ball milling of $\mathrm{Cu}$ and $\mathrm{Ta}$ powders, where a $\mathrm{Cu}$-based solid solution with 2 at $\%$ Ta was reported. ${ }^{52)}$ It is important to note that even this relatively low value is sufficient to achieve a thermodynamic stabilization of the nanocrystalline microstructure by grain boundary segregation. ${ }^{53-55)}$ Several different mechanisms have been

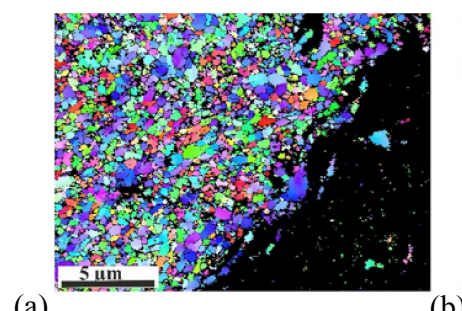

(a)

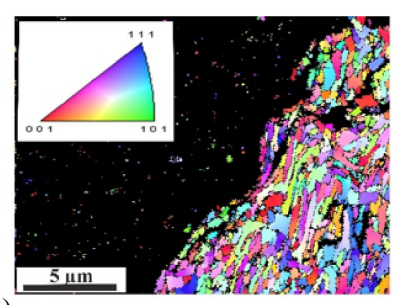

(b)

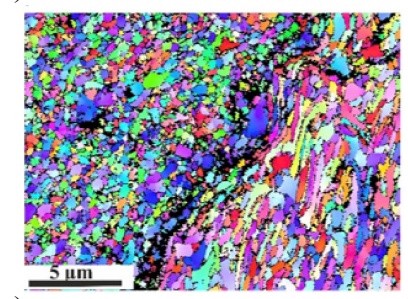

(c)

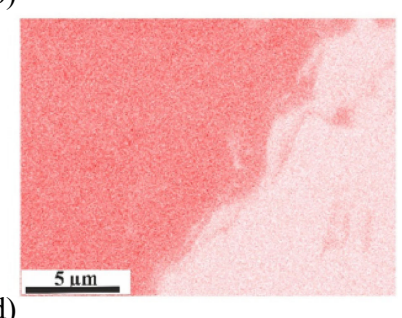

(d)

(e)

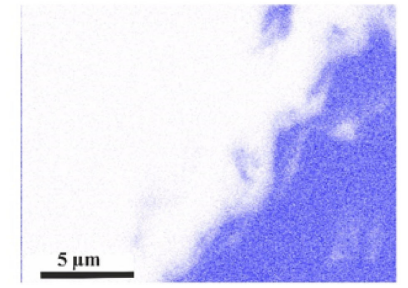

Fig. 6 EBSD maps of deformed $(\mathrm{a}-\mathrm{c}) \mathrm{Cu}-\mathrm{Ta}$. $\mathrm{Cu}$ lattice indexing in (a), the Ta lattice indexing in (b), and their combination in (c). Chemical maps of $\mathrm{Cu}(\mathrm{d})$ and $\mathrm{Ta}(\mathrm{e})$.

suggested over the years in order to explain shear-induced mixing in systems that are immiscible in equilibrium. Those mechanisms are either based on thermodynamic arguments that take interfaces (or finite size effects) into account ${ }^{56,57)}$ or on a kinetic description involving interface instabilities under shear ${ }^{58,59)}$ or a dislocation shuffle mechanism. ${ }^{60)}$ Concerning mechanisms based on dislocation transfer, one needs to consider that since $\mathrm{Cu}$ and $\mathrm{Ta}$ have different crystalline structures, specific orientation relationships would be required, which was not observed in our studies. Instead, the results suggest that the Ta atoms are shifted across the $\mathrm{Cu} / \mathrm{Ta}$ interfaces by dislocation-induced shearing of the atomic planes. Such forced atomic jumps may lead to a significant $\mathrm{Cu}-\mathrm{Ta}$ intermixing. It is astonishing that practically no $\mathrm{Cu}$ atoms are found inside of Ta grains. This observation indicates a significant asymmetry in mechanically-induced mixing, which might be due to the fact that the hardness of the Ta grains is higher than that of $\mathrm{Cu}$ grains and the shear deformation is mainly localized inside the soft grains. Still, a certain effect from $\mathrm{Cu}$ atoms on the Ta fraction does exist, since the hardness of the HPT-processed $\mathrm{Cu} / \mathrm{Ta}$ stacks is higher than that of similarly deformed pure Ta stacks.

The HPT-processed CuTa alloy turned out to show an enhanced thermal stability. In Fig. 8 the results of an EBSD/ SEM-EDX analysis of the deformed material after thermal annealing at $1000^{\circ} \mathrm{C}$ for $1 \mathrm{~h}$ are shown. This temperature corresponds to a homologous temperature of $0.94 T_{\mathrm{m}}\left(T_{\mathrm{m}}\right.$ is the melting point of copper). After the annealing treatment, the size of the coherently scattering domains increased only slightly, to about 20 to $30 \mathrm{~nm}$. The EBSD images substantiate further the stability of the ultra-fine grained microstructure, 

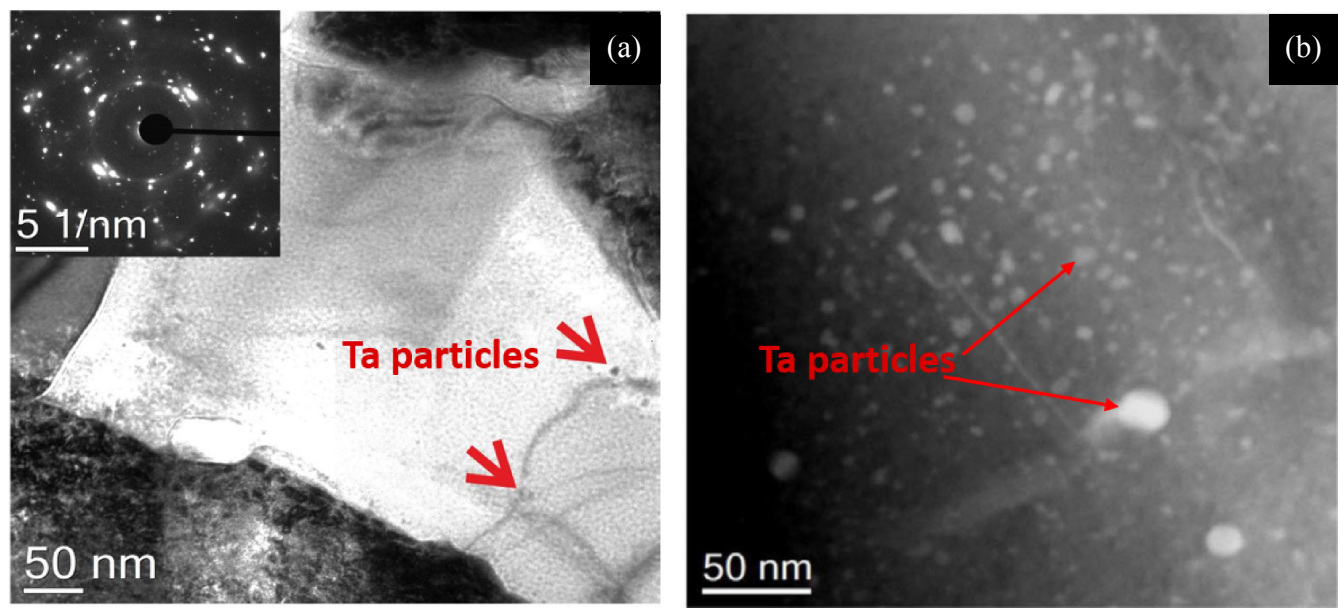

Fig. 7 (a) Bright-field TEM image of the HPT-processed $\mathrm{Cu}-\mathrm{Ta}$ alloy $(\mathrm{N}=150)$ after annealing at $1000^{\circ} \mathrm{C}(1 \mathrm{~h})$ : $\mathrm{Cu}$ grains, red arrows point to Ta particles inside of $\mathrm{Cu}$ crystallites; (b) HAADF image showing bright Ta particles in a dark $\mathrm{Cu}$ matrix.
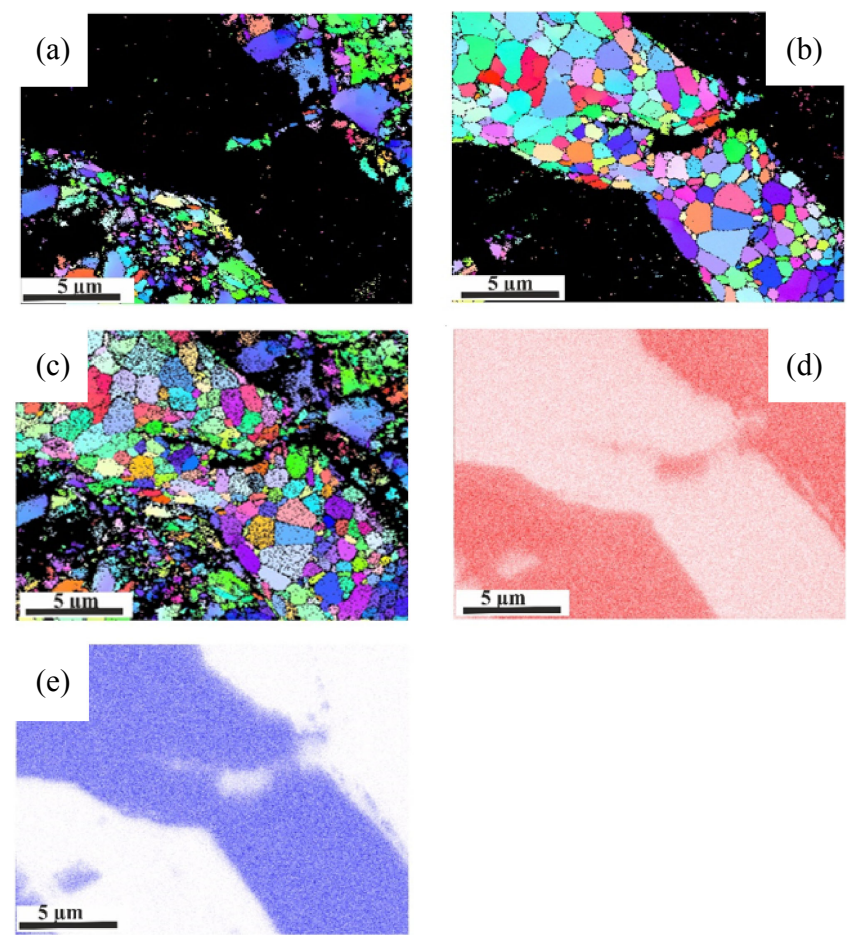

Fig. 8 EBSD maps of $\mathrm{Cu}-\mathrm{Ta}$ deformed and subsequently annealed at $1000^{\circ} \mathrm{C}(\mathrm{a}-\mathrm{c}) . \mathrm{Cu}$ lattice indexing in (a), the Ta lattice indexing in (b) and their combination (c). The chemical maps of $\mathrm{Cu}(\mathrm{d})$ and $\mathrm{Ta}(\mathrm{e})$.

especially in the FCC (Cu-based) phase, while some recovery is seem in the BCC (Ta-based) phase, Fig. 8. Nano-sized Ta particles inside of the $\mathrm{Cu}$ grains, Fig. 9, are found to be mainly responsible for effective dislocation and grain boundary pinning and thus for the microstructure stabilization. The remarkable difference between recovery processes in the $\mathrm{Cu}$-based and Ta-based partitions is explicitly seen by comparison of Figs. 8(a) and 8(b). The grain boundaries in Ta-based phase are straight, while the $\mathrm{Cu}-\mathrm{Cu}$ grain boundaries are broad, segmented with a strong strain contrast. It is probably the decomposition of the $\mathrm{Cu}$-Ta solid solution and the resulting segregation of $\mathrm{Ta}$ to grain boundaries with formation of Ta-rich areas, which induces such changes. We should indicate the formation of thin nano-scaled lamellas, Fig. 10(b).
After HPT processing, the hardness of the $\mathrm{Cu}-\mathrm{Ta}$ alloy is increased by a factor of two in comparison to pure Ta sheets, processed in the same way, although similar average grain sizes are found in both. This fact is most probably related to the presence of the nano-sized Ta particles, too. A small amount of $\mathrm{Cu}$ atoms in Ta grains as well as Ta atoms insides of $\mathrm{Cu}$ grains can also be responsible for additional solution hardening.

The high hardness and exceptional thermal stability indicate the efficiency of strain-induced mixing at low strain rates and low homologous temperatures. It further indicates that the final properties of a material might sensitively depend on the details of the processing pathway, even if severe deformation is involved as one of the processing steps.

\section{Grain Boundary Diffusion}

Radiotracer diffusion investigations of nanostructured and ultrafine grained materials produced by severe plastic deformation revealed extreme complexity and a strong inhomogeneity of the grain boundary structures in copper and copper-based alloys, ${ }^{8,61-64)}$ nickel, ${ }^{9,11)}$ or Ti. ${ }^{12)}$ (In these experiments, small amounts of solutes $-\mathrm{Zr}$ or $\mathrm{Pb}-$ were added on purpose to suppress grain growth during diffusion annealing in SPD-processed Cu-based alloys).

In Fig. 11 the diffusion data are presented as Arrhenius plots for pure $\mathrm{Cu},{ }^{61,65)} \mathrm{Cu}-1$ mass $\% \mathrm{~Pb}^{61)}$ and $\mathrm{Cu}-0.17$ mass $\% \mathrm{Zr}^{8)}$ alloys (a) and pure $\mathrm{Ni}^{9}, 11$ ) (b), while the homologous (reduced) temperature, $T / T_{\mathrm{m}}$, is indicated on the upper abscissa axis. Here $T_{\mathrm{m}}$ is the corresponding melting point of the metal and SPD processing has been performed at room temperature in all measurements, i.e. at $0.17 T_{\mathrm{m}}$ and $0.22 T_{\mathrm{m}}$ for $\mathrm{Ni}$ and $\mathrm{Cu}$, respectively.

Several remarkable results can be highlighted:

- At low homologous temperatures, below $0.23 T_{\mathrm{m}}$, shortcircuit diffusion in UFG Ni (blue points) is significantly, by orders of magnitude faster than GB diffusion in coarse grained nickel of the same (black line) or even higher (black dashed line) purity. And a noticeable deviation from the otherwise linear Arrhenius-type temperature dependence is observed at $T>400 \mathrm{~K}$ $\left(T>0.23 T_{\mathrm{m}}\right)$, Fig. 11(b). 

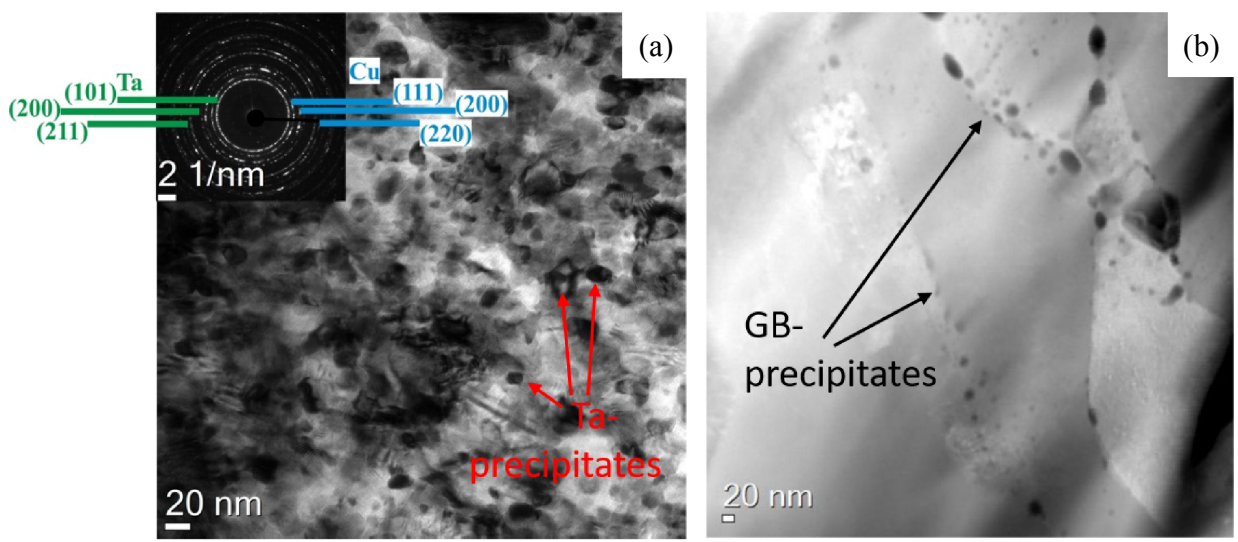

Fig. 9 TEM micrographs of a HPT-processed Cu50Ta50 alloy ( $\mathrm{N}=150$ ): (a) bright-field image; (b) High-angle annular dark-field (HAADF) image with strong chemical contrast shows contrast within grains and at grain boundaries. Insets show the corresponding SADPs.
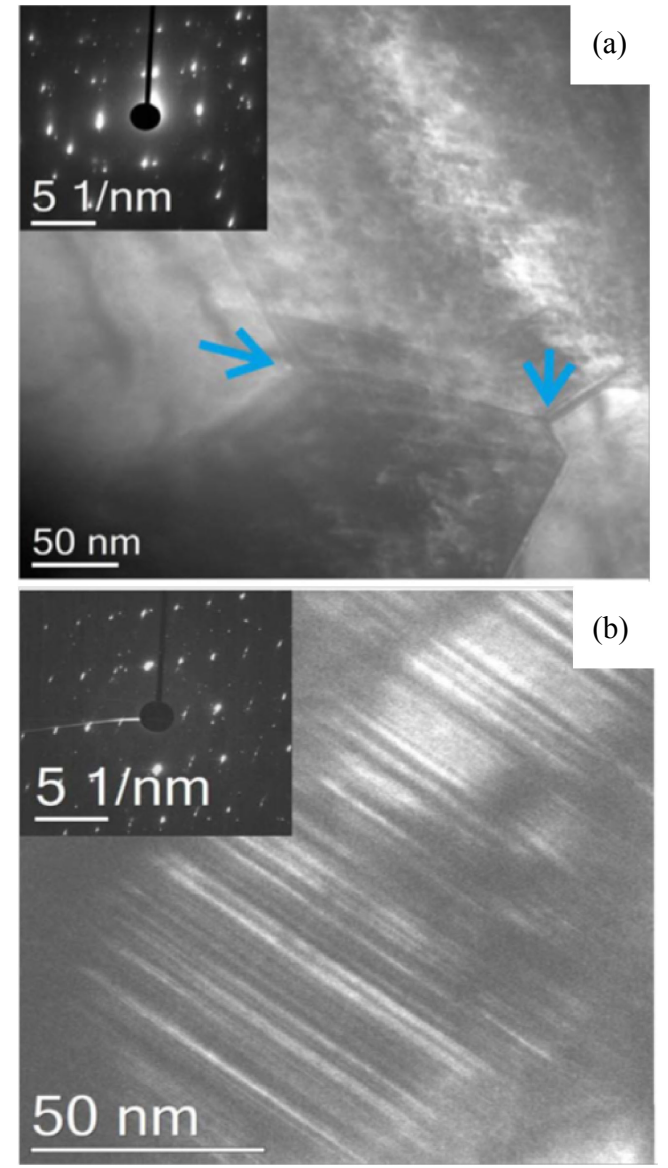

Fig. 10 Bright-field TEM images of the HPT-processed CuTa $(\mathrm{N}=150)$ after annealing at $1000^{\circ} \mathrm{C}(1 \mathrm{~h})$ : (a) Ta grains, blue arrows indicate triple junctions; (b) HAADF image showing bright Ta particles in a dark $\mathrm{Cu}$ matrix.

- Enhanced grain boundary diffusion in SPD-processed $\mathrm{Cu}$ is measured at homologous temperatures between $0.25-0.3 T_{\mathrm{m}}$, blue solid line in Fig. 11(a), and a hypothetical kink in the Arrhenius plot would correspond to the processing (room) temperature.

- A hierarchy of interfaces with significantly different diffusion properties ('slow' and 'fast') is established in ECAP-Ni and $\mathrm{Cu}$ that is most pronounced at $T>0.3 T_{\mathrm{m}}$.
- The 'slow' diffusion process represents the contribution of relaxed high-angle GBs (black solid lines).

- ECAP-processing of $\mathrm{Cu}$ and annealing treatment of ECAP-processed Ni induces a specific type of ultrafast diffusion paths (red dashed lines) which was unambiguously shown ${ }^{9,11,66)}$ to correspond to percolating, interconnected porosity in these materials.

The 'fast' diffusion paths in deformed Ni are unambiguously related to deformation-modified grain boundaries, ${ }^{9,11)}$ whereas their existence in SPD-processed $\mathrm{Cu}$ is still under debate. ${ }^{65)}$ It is important that diffusion measurements in pure $\mathrm{Cu}$ are performed in recrystallized microstructures. Do the fast paths in $\mathrm{Cu}$ (blue line in Fig. 11(a)) correspond to DMGBs or do they represent random high-angle grain boundaries, which appear after low-temperature recrystallization and are eliminated by annealing at higher temperatures during grain growth and grain boundary migration? Further data are required for a rigorous interpretation of the diffusion data in Fig. 11. One of the goals could be establishing of a direct correlation between the existence of DMGBs and modified mechanical properties of $\mathrm{Cu}$ or $\mathrm{Ni}$.

The diffusion data allows further estimates concerning the deformation-modified state of GBs. Based on self-diffusion data, the excess free energy of HEGB was estimated to be enhanced by about $30 \%$ with respect to the excess free energy of relaxed grain boundaries in the coarse-grained counterparts. These analyses and results have been described in detail. 7,11 )

\subsection{Correlation of GB structure and GB kinetic proper- ties}

In Fig. 12, TEM images (bright-field) of typical GBs in ECAP-processed $\mathrm{Cu}^{67)}$ and $\mathrm{Ni}^{68}$ are shown. A significant fraction of general GBs in UFG $\mathrm{Ni}$ and $\mathrm{Cu}$ after ECAP deformation exhibit a serrated structure and a wavy character (highlighted by red arrows) indicating a high density of defects incorporated into the boundary-near region and resulting residual stress/strain fields. However, there is a large fraction of straight, recovered GBs, especially in ECAP $\mathrm{Cu}$ (blue arrows).

The corresponding dark-field images reveal special localized contrast at the serrated GBs which is probably caused by extrinsic dislocations, kinks or steps at the grain 

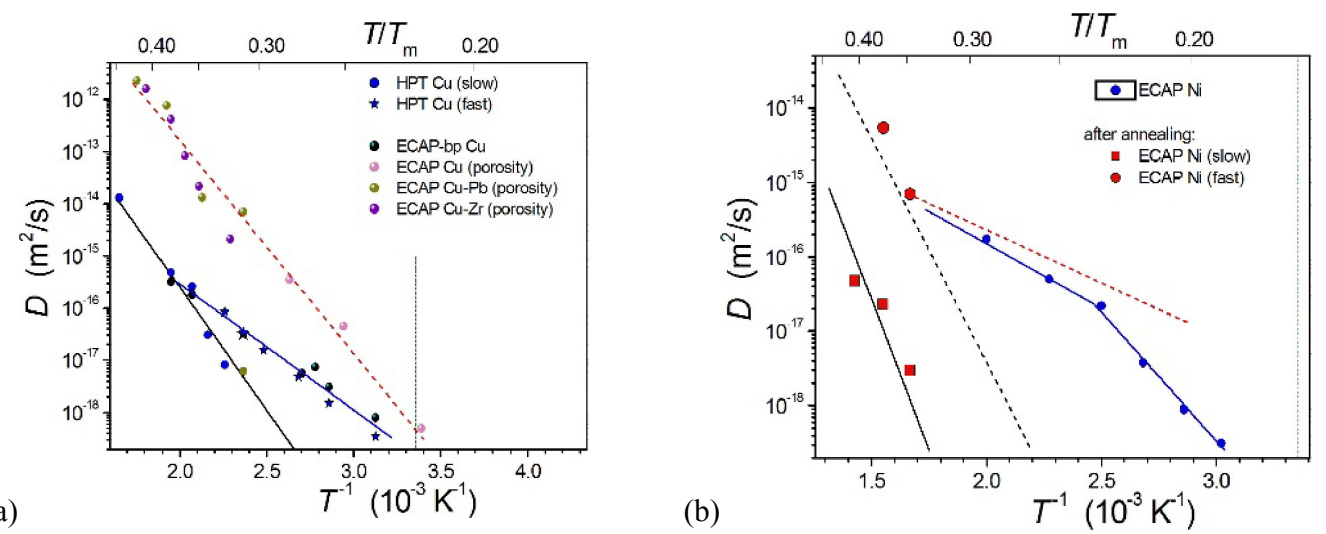

Fig. 11 Ni grain boundary diffusion in SPD-processed $\mathrm{Cu}^{61,65)}$ and $\mathrm{Cu}$-based alloys ${ }^{8,61)}$ (a) and in ECAP-deformed $\mathrm{Ni}^{9,11)}$ (b). Ni diffusion rates in annealed coarse-grained materials are shown by black solid lines and diffusion in SPD-processed materials are shown by blue solid lines. The red dashed lines show diffusion rates corresponding to internal porosity in the materials. The SPD processing temperature - room temperature in these cases - is indicated by vertical dashed lines.

(a)

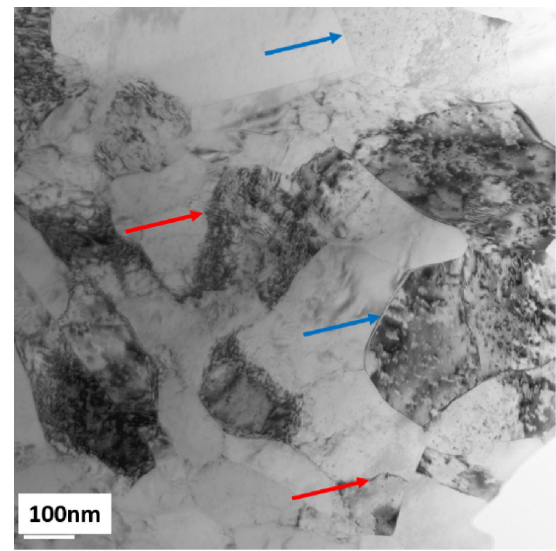

(c)

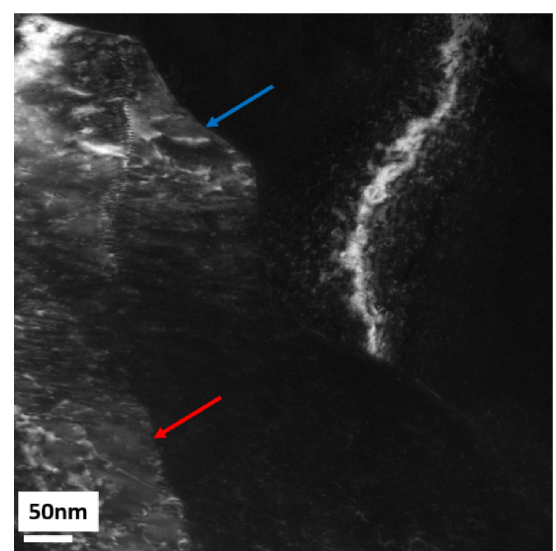

(b)

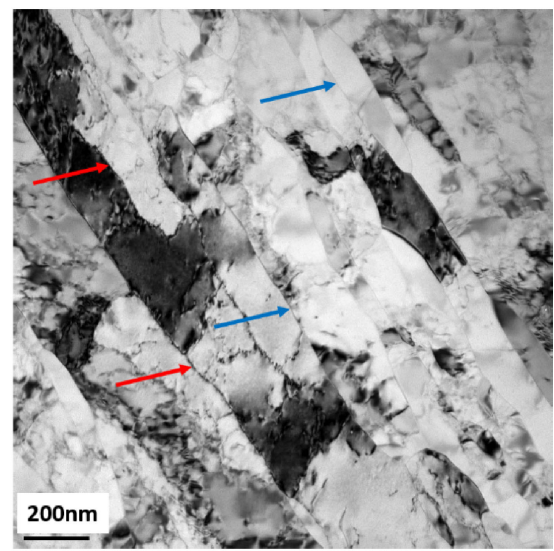

(d)

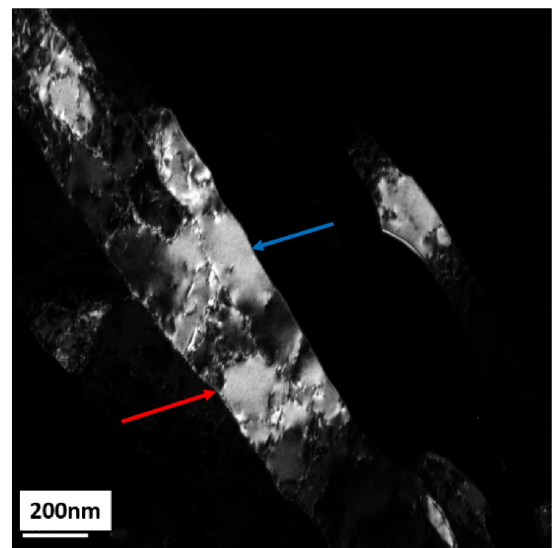

Fig. 12 Typical TEM micrographs of ECAP-produced UFG $\left.\mathrm{Cu}^{67}\right)(\mathrm{a}, \mathrm{c})$ and $\mathrm{Ni}^{68}(\mathrm{~b}, \mathrm{~d})$. The route BC4 was used and deformation was performed at room temperature. Both bright-field $(a, b)$ and dark-field (c, d) images are presented. One may distinguish two families of high-angle GBs. One kind of GBs appears to be straight, relaxed (blue arrows) and another type has a typical serrated contrast (red arrows).

boundaries induced by the severe plastic deformation. We highlight hereto that the atomic structure observations alone cannot prove (or reject) the deformation-modified character of the GBs since it is known that well-annealed GBs may also be faceted and dissociated at the atomic scale. ${ }^{69)}$

However, being combined with the diffusion measurements, these data substantiate the existence of a hierarchy of diffusion paths in UFG materials ranging from recovered, general high-angle GBs to DMGBs.

We emphasize that we are not claiming any direct relationship between any particular GB (observed by TEM,
Fig. 12) and the determined GB diffusivities, Fig. 11. The TEM study is a local technique, whereas by a diffusion experiment integral information is delivered. Only a qualitative correlation between the diffusion data and typical GB structures is highlighted here. Further studies are required especially with respect to properties which are sensitive to the GB state.

In Fig. 13, a high-resolution image of a high-angle grain boundary with a serrated contrast as that in Fig. 12 (red arrows) is presented. ${ }^{67)}$ Unfortunately, due to a strong Moiré contribution we were not able to perform an analysis of the 


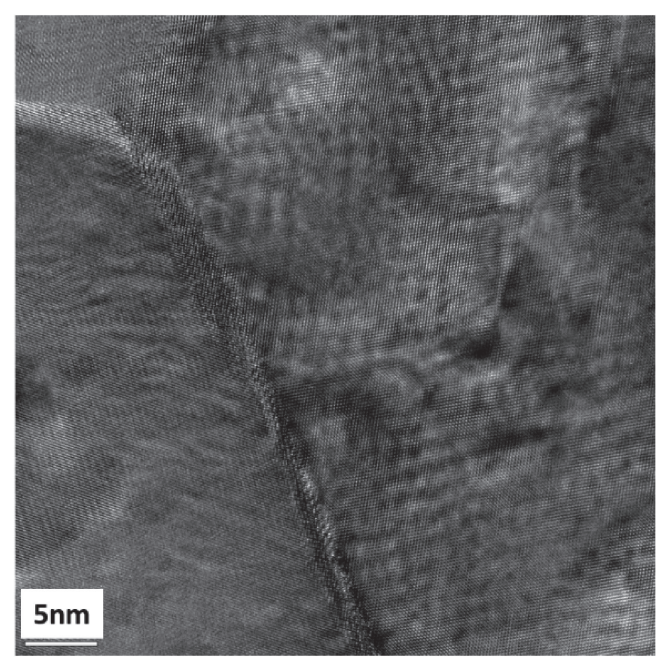

Fig. 13 High-resolution TEM micrograph of ECAP-produced UFG $\mathrm{Cu}$ deformed via the route $\mathrm{BC}_{4}$ at room temperature. ${ }^{67)} \mathrm{A}$ grain boundary with the serrated contrast (as indicated by red arrows in Fig. 12(a)) is shown here. A strong Moiré-contrast hinders an analysis of the strain fields around the interface.

local strain field at the boundaries similar to those in our previous work on $\mathrm{Pd}-\mathrm{Ag} .{ }^{70}$ )

One may assume that the localized strain contrast (as that in Fig. 12, red arrows) corresponds to the incorporation of lattice dislocations and the appearance of intrinsic GB dislocations. A full analysis of such interfaces was done in Ref. 70) for a HPT-processed Pd-Ag alloy.

The diffusion data suggest a deformation-modified state of GBs in UFG Ni induced by severe plastic deformation. This state is relaxed at $T>400 \mathrm{~K}$. The majority of GBs after annealing at $T \geq 500 \mathrm{~K}$ appear well-relaxed. However, ultrafast diffusivities were still found at these temperatures. We conclude that the GBs preserve their deformation-modified character even after these annealing treatments. However, the origin and nature of the fast diffusion along these boundaries after annealing seem to be related to the interaction of the grain boundaries with mobile defects during recovery and are fundamentally different from those in the as-prepared state, which calls for a detailed examination.

\subsection{Evolution of the deformation-induced modifications of GBs}

In parallel to substantial grain refinement, the severe plastic deformation induces a huge amount of further defects in the materials, including vacancies, interstitial atoms, dislocations, dislocation walls, pores, etc. The evolution of these defects as a result of subsequent heat treatment was found to affect substantially grain boundary diffusion. The impact of heat treatment on the deformation-modified general high-angle grain boundaries was investigated by accurate radiotracer self-diffusion measurements in ECAP-processed Ni, Fig. 14(a). Annealing at $400 \mathrm{~K}$ enhances first the GB diffusion rates via formation of ultra-fast diffusion paths with increased free volume, red dotted line. Annealing at higher temperatures results in relaxation of grain boundaries and simultaneous redistribution of impurity atoms which is known to impact substantially GB self-diffusion ${ }^{71,72)}$ and to trigger relaxation of these diffusion paths. A correlation between the GB diffusion kinetics, internal friction, microstructure evolution and length changes of the samples was established, Fig. 14(b).

Difference dilatometry, ${ }^{73)}$ differential scanning calorimetry (DSC), and mechanical spectroscopy ${ }^{11)}$ revealed distinct contributions of different defect types and processes such as vacancies, dislocations, grain boundaries and grain-boundary relaxation. These processes were distinguished due to their distinct kinetics. The data were quantified in combination with a detailed characterization of the microstructure ${ }^{73)}$ that allowed to determine the absolute vacancy concentration, the dislocation density, the grain boundary expansion and the excess of grain boundary expansion in ECAP-processed nickel. ${ }^{73)}$

Three distinct peaks of temperature-dependent heat flux, length changes and mechanical damping were observed, $P_{1-}$
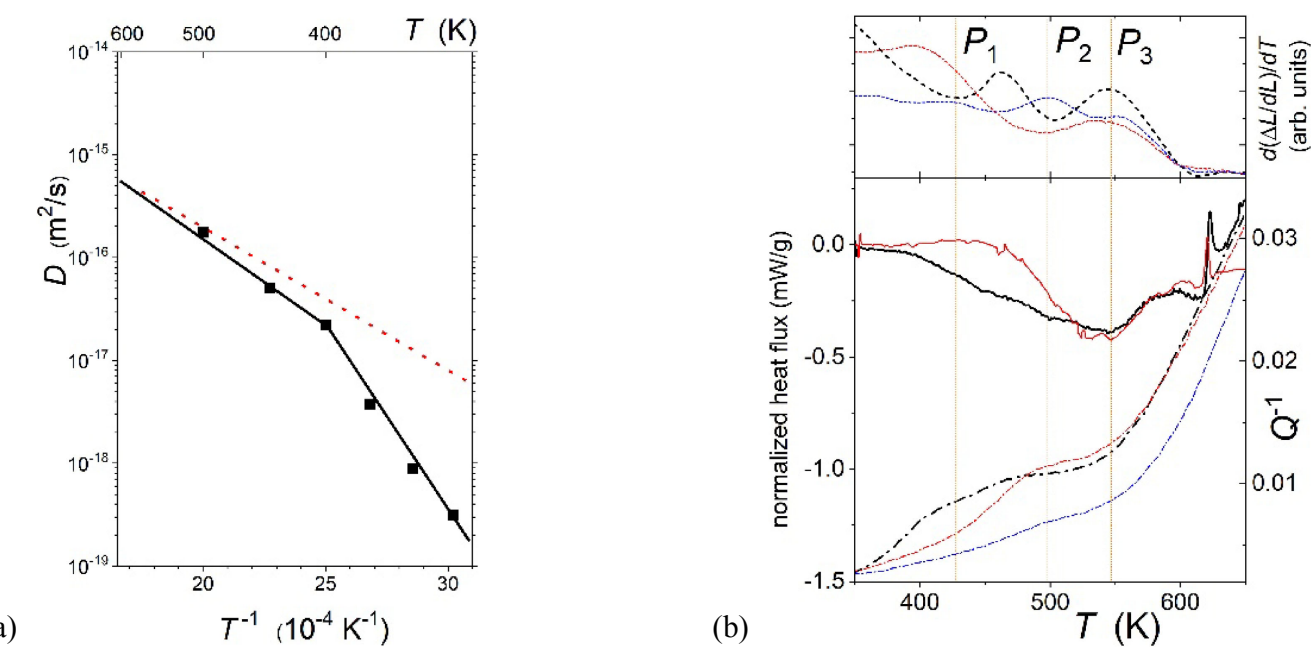

Fig. 14 Impact of post-deformation annealing on grain boundary diffusion $D$ of $\mathrm{Ni}$ (a) and on heat flux (solid lines), length changes, $d(\Delta L / d L) / d T$ (dashed lines) and mechanical damping, $Q^{-1}$ (dotted-dashed lines) (b) in ECAP-processed Ni. In (a) black solid symbols represent the diffusion coefficients measured in as-deformed $\mathrm{Ni}$ and red dotted line correspond to those after annealing at $400 \mathrm{~K}$. In (b) black, red and blue lines correspond to the measurements done on as-deformed, annealed at $400 \mathrm{~K}$ and annealed at $500 \mathrm{~K}$ samples, respectively. 
$P_{3}$, and attributed to vacancy annihilation, formation of vacancy-impurity complexes and dislocation reactions, respectively. ${ }^{11,73)}$

\subsection{Nature of deformation-induced diffusion enhance- ment}

The nature of the deformation-induced diffusion enhancement was experimentally investigated in the case of ECAPprocessed $\alpha-\mathrm{Ti}^{12}{ }^{12}$ In fact, this is one of the most important papers on diffusion properties of deformation-modified interfaces which clarifies unambiguously the underlying mechanism. That investigation demonstrates that random high-angle grain boundary could mechanically be driven in a metastable state which is characterized by a specific distribution of deformation-induced defects. Simultaneously, the role of deformation-induced excess free volume probably as localized defects of the GB structures, which do not affect the macroscopic degrees of freedom and do not change the given misorientation/inclination of the interface, was highlighted.

The key point of that study was the usage of so-called 'ultra-fast' diffusion transition metals, specifically Co, in the hep lattice of $\alpha$-Ti. ${ }^{74)}$ Even the grain boundary diffusion rate of $\mathrm{Co}$ in $\alpha$-Ti exceeds that of host atoms by 7 to 8 orders of magnitude. ${ }^{74)}$ Thus, using the Co atoms one can probe the energy landscape in titanium grain boundaries on time scales when host atoms are immobile. This gives direct access to examine even metastable states of the corresponding interfaces.

In Ref. 12), it was shown that grain boundary diffusion of interstitially diffusing Co is somewhat decreased in the UFG state, while that of substitutionally diffusing $\mathrm{Ag}$ is dramatically enhanced, Fig. 15. Thus, these are free volume defects (e.g. deformation-induced vacancies) which accumulate at deformation-modified interfaces proving vacancy-like traps and suppressing diffusion of interstitials and simultaneously enhancing diffusion of oversized atoms. ${ }^{12)}$ The deformation-induced excess volume was analyzed for ECAP processed Ni via combined dilatometry and DSC measurements with detailed microstructure characterization. ${ }^{73)}$

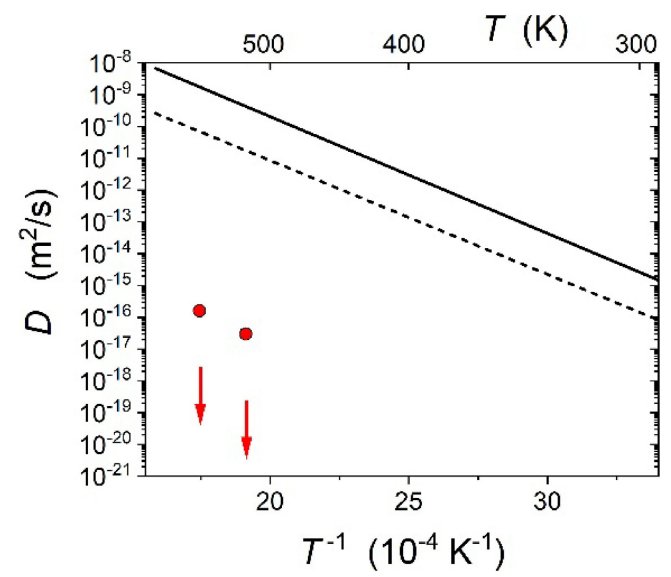

Fig. 15 Diffusion of Co (lines) and Ag (symbols) in coarse-grained (solid line, Co and vertical bars, Ag) and ultra-fine grained (dashed line, Co and circles, Ag) $\alpha$-Ti. ${ }^{12}$ ) The upper estimates of GB diffusion of $\mathrm{Ag}$ in annealed coarse-grained $\alpha$-Ti are indicated (arrows).

\subsection{Impact of second phase particles}

The kinetics of phase transformation and microstructure formation in materials is often determined by the diffusion rate of its solutes. In a real material, we often meet a situation of mechano-chemical coupling, when size and chemical composition of the growing particles affect the elastic strains and stresses around them, which in turn influence the component redistribution and elements' fluxes. Extremely complex will be situations in severely deformed alloys prone to particle formation. Such a two-way coupling phenomenon was recently investigated using the radioisotope ${ }^{57} \mathrm{Co}$ as a probe of the impact of forming $\mathrm{Al}_{3} \mathrm{Sc}$-based nano-precipitates on the diffusion in Al-based alloys. ${ }^{75)}$ Under ECAP processing and post-deformation annealing, different microstructures and precipitate sizes were obtained.

Short-circuit diffusion along grain boundaries in the socalled C-type kinetic regime was used to ensure a welldefined distance of the diffusion path from the precipitates and to prohibit particles' evolution during measurements. The radiotracer measurements revealed a remarkable nonmonotonic dependence of the diffusion rates on the annealing temperature, Fig. 16.

Though Co is definitely a substitutional solute in $\mathrm{Al}$ and diffuses via a vacancy-mediated mechanism, including grain boundaries, ${ }^{76}$ ) its diffusion rate is found to be strongly depressed in ECAP-processed material with respect to the diffusion coefficients measured in pure Al, Fig. 16 - in an obvious contradiction to the trends presented in the previous sections for $\mathrm{Ni}$ and $\mathrm{Cu}$ ! These diffusion rates drop further after annealing treatments, even at temperatures above $0.8 T_{\mathrm{m}}$, when the deformation-induced modifications are definitely removed. Only after annealing at even higher temperatures, i.e. at $0.94 T_{\mathrm{m}}$, the diffusion rate of Co approaches that observed in pure Al.

This unusual behavior has been fully explained by an $\mathrm{ab}$ initio informed diffusion model that considers formation of second phase $\mathrm{Al}_{3}(\mathrm{Sc}, \mathrm{Zr})$ particles at the interfaces, appearance of the elastic stresses around the coherent and non-coherent precipitates, and the evolution of the latter in the course of annealing. ${ }^{75)}$

3.5 Model of GB diffusion in deformation-modified GBs

Grain boundary structure-property relationship is a long standing problem ${ }^{77)}$ and a subject of intensive research. ${ }^{78-80}$ ) As a common wisdom one can state that GB diffusion is drastically enhanced with transition from low-angle to highangle grain boundaries. ${ }^{81)}$ Furthermore, there exist prominent cusps at specific misorientations corresponding to special GBs. ${ }^{82}$ ) Thus, having specified a given misorientation axis, the grain boundary diffusion rates can be related to geometric characteristics of the interfaces in the given pure metal, such as misorientation ${ }^{83,84)}$ and inclination. ${ }^{85)}$ One has to note that already small deviations from the perfect low-Sigma orientations, like Sigma-3 or Sigma-5, affect the diffusion rates considerably. ${ }^{83)}$ Furthermore, grain boundary diffusion along a Sigma-3 boundary is significantly enhanced when the GB plane is inclined to the ideal symmetric position by more than $20^{\circ} .^{85)}$

Is GB diffusion a unique function of the given geometric parameters of the interface (misorientation axis and angle, 

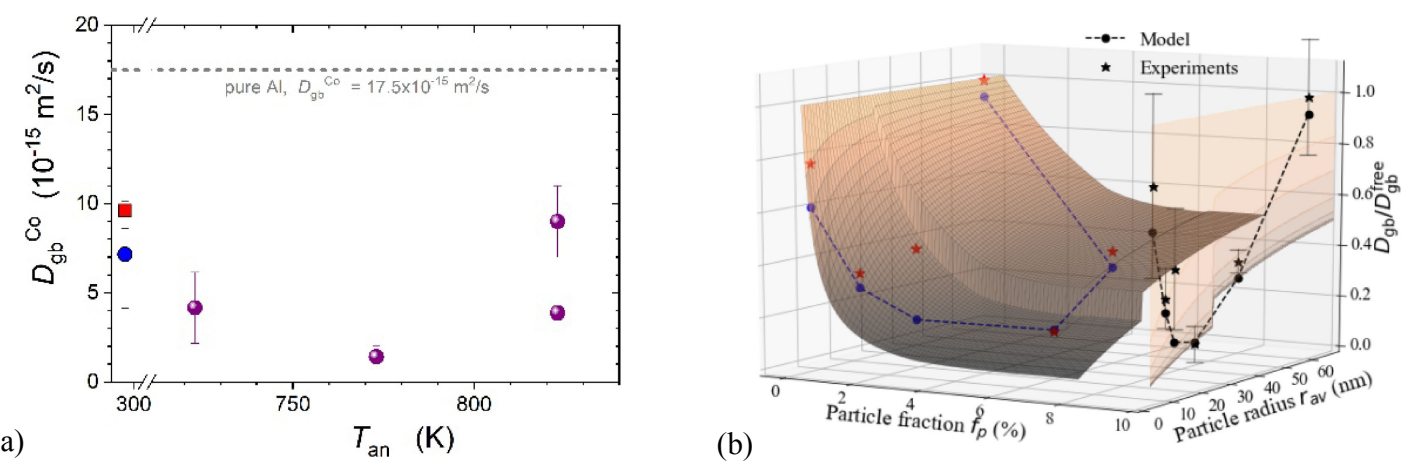

Fig. 16 (a) The diffusion coefficient of $\mathrm{Co}$ in the ECAP-processed Al alloy as a function of the post-deformation annealing temperature Tan (spheres). Co diffusion in pure Al is shown by the dashed line and those after extrusion and ECAP-processing (without annealing, Tan is set to the room temperature) are shown by the square and circle, respectively. (b) 3D surface showing the predicted variation of the diffusion coefficient of Co (normalized with respect to the diffusion coefficient in the stress-free state, $D_{\mathrm{gb}}=D_{\mathrm{gb}}$ free) with the particle size and the particle fraction. The filled stars represent the measured values. The dashed blue line connects the model predictions on the $3 \mathrm{D}$ surface for the experimentally determined values of particle density and particle size. The measured and predicted values are projected on to the front plane with the black dashed line joining the model predictions, too.

and the inclination) when the chemical degrees of freedom are not considered? (Segregation of residual impurities and alloying elements affect the GB diffusion rates, ${ }^{71,72)}$ however we will not include such analysis in the present consideration). Accurate GB diffusion measurements and dedicated atomistic simulations discovered the existence of GB phase transitions in pure $\mathrm{Cu} \mathrm{GBs} .{ }^{86-88)}$ The important feature is that the different GB diffusion rates and different GB structures correspond to the same geometrical degrees of freedom for the given interface.

In previous sections we have shown that the SPD processing modify the GB diffusion rates introducing modifications of the GB structure. We are highlighting that fully relaxed and deformation-modified states could generally be introduced for interfaces with the same macroscopic characteristics. The concept is similar to the idea of different microstates for interfaces which could be introduced by external action, e.g. by irradiation without modification of the macroscopic degrees of freedom. ${ }^{80}$ )

How the interface structure is modified so that GB diffusion is enhanced by orders of magnitude keeping the misorientation parameters fixed? Recently, a phenomenological model has been proposed ${ }^{11)}$ which assumes that the SPD processing modifies the GB structure, introducing local areas with an increased extra free volume interspersed with non-modified areas with the original GB structure. Thus, the modifications are assumed to be confined to one-dimensional (line-type, possibly curved) objects locked by non-modified areas (which may be associated with GB facets with the crystallography corresponding to relaxed state of the interfaces).

A schematic drawing in Fig. 17 visualizes this phenomenological model. The bright/dark contrast scales with the amount of a local free volume at the given location within the GB plane. The enhanced diffusion is confined to some linear defects (percolating over the GB plane, thus enabling longrange diffusion) which are separated by areas with structures corresponding to the relaxed high-angle GB as found in coarse-grained polycrystals. Such positions of good match between the neighboring crystals pin highly defective regions introduced by deformation, which are characterized by an extra excess volume and additional elastic strain fields (often

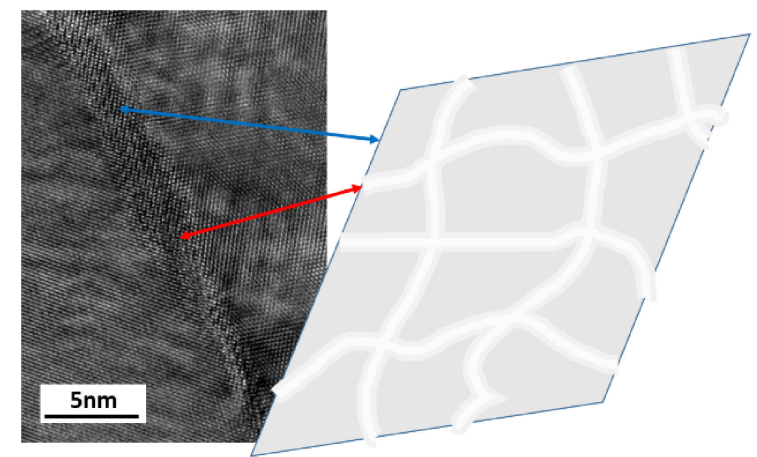

Fig. 17 Schematic plane-view of a non-homogeneous distribution of the excess free volume in a deformation-modified high-angle GB. The deformation-induced distortion is localized to channels (light gray) where the excess free volume exceeds the values typical for a relaxed high-angle GB. The undistorted (relaxed) regions are colored in gray. Such areas in a high-angle $\mathrm{GB}$ in ECAP-processed $\mathrm{Cu}$ are specified for its cross-section view.

reported for SPD proceeded materials ${ }^{70,89)}$ ). The phenomenologically introduced linear defects might represent GB disconnections ${ }^{80)}$ or GB extrinsic dislocations. ${ }^{6)}$ Since the GB diffusion measurements on ECAP Ti have unambiguously proven the incorporation of extra free volume as a main vehicle for diffusion of substitutional atoms, ${ }^{12)}$ we are forced to conclude that the linear defects - highly probable GB disconnections - have to incorporate excess free volume in addition to the value which is typical for general (relaxed) high-angle GBs.

The phenomenological model explains elegantly several experimental facts:

- a relatively small activation enthalpy of self-diffusion in ECAP Ni, ${ }^{9}$ which amounts to about half of the respective value for general relaxed high-angle GBs in annealed coarse-grained polycrystals; $;^{71,72)}$

- relatively sluggish relaxation of the deformationinduced modifications ${ }^{9)}$ which is governed by GB diffusion in the GB areas of "good match" (graycolored in Fig. 17);

- the absence of a direct correlation of the macroscopic degrees of freedom with the existence of the 
deformation-modified state of the given interface;

- the existence of deformation-induced modifications even for Sigma-3 twin boundaries..$^{90}$

\subsection{Porosity in SPD materials}

Severe plastic deformation is shown above to induce excess volume in metallic samples in the form of vacancies (vacancy clusters), dislocations and GB excess volume (including the deformation-modified part). Furthermore, it was shown that individual pores and so-called percolating porosity is introduced in $\mathrm{Cu}$ and $\mathrm{Cu}$-based alloys by ECAP ${ }^{66}$ ) or HPT ${ }^{91)}$ processing. These defects were revealed by TEM, SEM combined with FIB milling, and positron annihilation analyses. Most important, the radiotracer diffusion measurements allowed to estimate the volume fraction of the percolating free volume at about $2 \times 10^{-6}$.

The application of back pressure allows first (during the first 4 passes of route $\mathrm{B}_{\mathrm{C}}$ ) to suppress the formation of the percolating porosity, which however appears inevitably after larger numbers of ECAP passes. ${ }^{92)}$

The percolating porosity in SPD-processed $\mathrm{Cu}$ reveals exceptional stability against annealing, e.g., it is found to withstand the annealing treatments up to $1073 \mathrm{~K}$ for several hours in purified $\mathrm{Ar}$ atmosphere, ${ }^{93}$ despite significant microstructure transformations. Only annealing treatments at $1313 \mathrm{~K}$ in $\mathrm{Ar}$ or relatively short heat treatments at $427 \mathrm{~K}$ in a hydrogen-containing atmosphere removes the percolating porosity. The porosity closing can be triggered by the application of a quasi-hydrostatic pressure of $1 \mathrm{GPa}$ at $423 \mathrm{~K}^{93)}$

Interesting insights into mechanisms of the porosity development and healing during severe plastic deformation of pure $\mathrm{Cu}$ were gained recently by Qi et al. ${ }^{94)}$ Tricky experiments with holes drilled before processing and without holes revealed different evolutions of the volume fraction of the percolating porosity in the HPT-processed disks.

This porosity can substantially complicate the analysis of the diffusion measurements resulting in enhanced grain boundary diffusion rates after annealing treatment, as it was found in ECAP-processed $\mathrm{Ni},{ }^{9}$ ) see Fig. 11, too. The impact of the deformation-induced porosity on the mechanical properties of the UFG materials could not only be deteriorating, as porosity in superplastic applications is common.

\section{Conclusions}

Structural and kinetic properties of deformation-modified grain boundaries and microstructures have been reviewed. The high rates of defect creation during severe plastic deformation at low homologous temperatures in combination with the intrinsic heterogeneity of deformation-induced processes and transformations creates complex hierarchies of microstructure elements and can be used for creating multimodal microstructures or instable states of matter with very high kinetic stabilities and unique property combinations.

The available data substantiate also the intrinsic heterogeneity of defect production and defect-induced modifications of the local interface structures in SPDprocessed materials. A fraction of high-angle grain boundaries attains a metastable, deformation-modified state which is characterized by enhanced atomic transport, increased (but localized to interfaces) elastic strain fields and corresponding stresses.

Well-dedicated measurements of tracer diffusion using $\mathrm{Co}$ and $\mathrm{Ag}$ atoms as sensitive probes of local structure modifications in ECAP-processed $\alpha$-Ti revealed unambiguously the presence of localized excess volume in such boundaries. The deformation-modified state occurred to be relatively stable - given that the room temperature conditions correspond to a relatively low homologous temperature. The key feature is the above mentioned heterogeneity of excess volume localization that enables highly enhanced rates of atomic transport and relatively reduced rates of relaxation of the deformation-induced modifications.

\section{Acknowledgments}

Financial support of German Science Foundation (DFG) is acknowledged.

\section{REFERENCES}

1) M.J. Zehetbauer and Y.T. Zhu, eds.: Bulk Nanostructured Materials, (Wiley-VCH, Weinheim, Germany, 2009).

2) Y. Estrin and A. Vinogradov: Acta Mater. 61 (2013) 782-817.

3) R.Z. Valiev, Y. Estrin, Z. Horita, T.G. Langdon, M.J. Zehetbauer and Y.T. Zhu: Mater. Res. Lett. 4 (2016) 1-21.

4) S. Kahofer, M.J. Zehetbauer, H. Danninger, E. Schafler, M. Kerber and J. Horky: Mater. Sci. Forum 667-669 (2011) 151-156.

5) R. Valiev, R. Islamgaliev and I. Alexandrov: Prog. Mater. Sci. 45 (2000) 103-189.

6) A. Nazarov, A. Romanov and R.Z. Valiev: Acta Metall. Mater. 41 (1993) 1033-1040.

7) X. Sauvage, G. Wilde, S.V. Divinski, Z. Horita and R.Z. Valiev: Mater Sci. Eng. A 540 (2012) 1-12.

8) Y. Amouyal, S.V. Divinski, Y. Estrin and E. Rabkin: Acta Mater. 55 (2007) 5968-5979.

9) S.V. Divinski, G. Reglitz, H. Rösner, Y. Estrin and G. Wilde: Acta Mater. 59 (2011) 1974-1985.

10) G.P. Grabovetskaya, Y.R. Kolobov, K.V. Ivanov and N.V. Girsova: Phys. Met. Metallogr. 94 (2002) 37.

11) S.V. Divinski, G. Reglitz, I. Golovin, M. Peterlechner and G. Wilde: Acta Mater. 82 (2015) 11-21.

12) J. Fiebig, S.V. Divinski, H. Rösner, Y. Estrin and G. Wilde: J. Appl. Phys. 110 (2011) 083514.

13) M.B. Kerber, M.J. Zehetbauer, E. Schafler, F.C. Spieckermann, S. Bernstorff and T. Ungar: JOM 63 (2011) 61-70.

14) M.J. Zehetbauer and D. Trattner: Mater. Sci. Eng. 89 (1987) 93-101.

15) E. Schafler: Scr. Mater. 62 (2010) 423-426.

16) E. Schafler: Scr. Mater. 64 (2011) 130-132.

17) M. Kawasaki, I.J. Beyerlein, S.C. Vogel and T.G. Langdon: Acta Mater. 56 (2008) 2307.

18) P. Král, J. Dvorák, P. Sedá, A. Jäger and V. Sklenicka: Rev. Adv. Mater. Sci. 31 (2012) 138-144.

19) M.A. Meyers, A. Mishra and D.J. Benson: Prog. Mater. Sci. 51 (2006) 427-556.

20) D. Prokoshkina, A. Moros, G. Reglitz, G.P. Dinda, D.D. Kuznetsov, V.V. Popov, A.V. Stolbovsky, E.V. Shorohov, S.V. Divinski and G. Wilde: Adv. Eng. Mater. 17 (2015) 1842-1852.

21) R.Z. Valiev, N.A. Enikeev, M.Y. Murashkin, V.U. Kazykhanova and X. Sauvage: Scr. Mater. 63 (2010) 949-952.

22) R.Z. Valiev, M.Y. Murashkin and I.P. Semenova: Metall. Mater. Trans. A 41 (2010) 816-822.

23) L. Balogh, T. Ungar, Y. Zhao, Y.T. Zhu, Z. Horita, C. Xu and T.G. Langdon: Acta Mater. 56 (2008) 809-820.

24) Y.T. Zhu, X.Z. Liao and X.L. Wu: Prog. Mater. Sci. 57 (2012) 1-62. 
25) A.L. Oppedal, H. El Kadiri, C.N. Tome, G.C. Kaschner, S.C. Vogel, J.C. Baird and M.F. Horstemeyer: Int. J. Plasticity 30-31 (2012) 41-61.

26) S.V. Bobylev and I.A. Ovid'ko: Acta Mater. 88 (2015) 260-270.

27) Y. Ivanisenko, L. Kurmanaeva, J. Weissmueller, K. Yang, J. Markmann, H. Rosner, T. Scherer and H.J. Fecht: Acta Mater. 57 (2009) 3391-3401.

28) X.Z. Liao, F. Zhou, E.J. Lavernia, S.G. Srinivasan, M.I. Baskes, D.W. He and Y.T. Zhu: Appl. Phys. Lett. 83 (2003) 632-634.

29) T. Watanabe: J. Mater. Sci. 46 (2011) 4095-4115.

30) V. Randle and G. Owen: Acta Mater. 54 (2006) 1777-1783.

31) T. Watanabe: Res. Mechanica 11 (1984) 47.

32) F. Emeis, M. Peterlechner, S.V. Divinski and G. Wilde: Acta Mater. 150 (2018) 262-272.

33) C. Wang, X. Liu, M. Jiang, I. Ohnuma, R. Kainuma and K. Ishida: J. Phys. Chem. Solids 66 (2005) 256.

34) Y. Iguchi, G.L. Katona, C. Cserháti, G.A. Langer and Z. Erdélyi: Acta Mater. 148 (2018) 49-54.

35) E. Osswald: Z. Phys. 83 (1933) 55

36) F. Nabarro: Proc. Phys. Soc. 58 (1946) 669.

37) I. Harris, I. Dillamore, R. Smallman and B. Beeston: Philos. Mag. 14 (1966) 325.

38) F. Emeis: PhD thesis, Institute of Materials Physics, University of Muenster, Germany, (2019).

39) F. Emeis, J. Leuthold, K. Spangenberg, M. Peterlechner and G. Wilde: Adv. Eng. Mater. 21 (2019) 1801214.

40) in-house developed software, "Pythorient": available at https://github. com/joernleu/Pythorient.

41) J. Rogal, S.V. Divinski, M.W. Finnis, A. Glensk, J. Neugebauer, J.H. Perepezko, S. Schuwalow, M.H.F. Sluiter and B. Sundman: Phys Status Solidi B 251 (2014) 97-129.

42) K.S. Raju, V.S. Sarma, A. Kauffmann, Z. Hegedus, J. Gubicza, M Peterlechner, J. Freudenberger and G. Wilde: Acta Mater. 61 (2013) 228-238.

43) R. Wirth and H. Gleiter: Acta Metall. 29 (1981) 1825.

44) A. Gaganov, J. Freudenberger, E. Botcharova and L. Schultz: Mater. Sci. Eng. A 437 (2006) 313.

45) D.A. Porter and K.E. Easterling: Phase Transformation in Metals and Alloys, (Chapman and Hall, London, 1992).

46) Y.S. Li, Y. Zhang, N.R. Tao and K. Lu: Scr. Mater. 59 (2008) 475.

47) Y.H. Zhao, X.Z. Liao, Z. Horita, T.G. Langdon and Y.T. Zhu: Mater. Sci. Eng. A 493 (2008) 123.

48) Y.G. Ko, S. Namgung, B.U. Lee and D.H. Shin: J. Alloys Compd. 504 (2010) S448.

49) N. Ibrahim, M. Peterlechner, F. Emeis, M. Wegner, S. Divinski and G Wilde: Mater. Sci. Eng. A 685 (2017) 19-30.

50) Y. Beygelzimer, R. Kulagin, L.S. Toth and Y. Ivanisenko: Beilstein J. Nanotechnol. 7 (2016) 1267-1277.

51) L. Vegard: Z. Phys. 5 (1921) 17.

52) K.A. Darling, A.J. Roberts, Y. Mishin, S.N. Mathaudhu and L.J. Kecskes: J. Alloys Compd. 573 (2013) 142-150.

53) K.A. Darling, B.K. Van Leeuwen, J.E. Semones, C.C. Koch, S.N.M. Scattergood and L.J. Kecskes: Mater. Sci. Eng. 528 (2011) 4365-4371.

54) N.Q. Vo, J. Schafer, R.S. Averback, K. Albe, Y. Ashkenazy and P. Bellon: Scr. Mater. 65 (2011) 660-663.

55) X. Sauvage, F. Wetscher and P. Pareige: Acta Mater. 53 (2005) 2127 2135.

56) C. Gente, M. Oehring and R. Bormann: Phys. Rev. B 48 (1993) 13244

57) G. Veltl, B. Scholz and H. Kunze: Mater. Sci. Eng. A 134 (1991) 1410 1413.

58) P. Bellon and R.S. Averback: Phys. Rev. Lett. 74 (1995) 1819-1822.

59) Yu. Ivanisenko, W. Lojkowski, R.Z. Valiev and H.-J. Fecht: Acta Mater. 51 (2003) 5555-5570.

60) D. Raabe, S. Ohsaki and K. Hono: Acta Mater. 57 (2009) 5254-5263.

61) J. Ribbe, G. Schmitz, Y. Amouyal, Y. Estrin and S.V. Divinski: Mater. Sci. Forum 584-586 (2008) 380-386.
62) J. Ribbe, G. Schmitz, D. Gunderov, Y. Estrin, Y. Amouyal, G. Wilde and S.V. Divinski: Acta Mater. 61 (2013) 5477-5486.

63) J. Ribbe, G. Schmitz, H. Rösner, R. Lapovock, Y. Estrin, G. Wilde and S.V. Divinski: Scr. Mater. 68 (2013) 925-928.

64) J. Ribbe, D. Baither, G. Schmitz and S.V. Divinski: Scr. Mater. 61 (2009) 129-132.

65) M. Wegner, J. Leuthold, S.V. Divinski and G. Wilde: (2019) in preparation.

66) S.V. Divinski, J. Ribbe, D. Baither, G. Schmitz, G. Reglitz, H. Rösner, K. Sato, Y. Estrin and G. Wilde: Acta Mater. 57 (2009) 5706-5717.

67) J. Ribbe: PhD Thesis, University of Münster, Germany, (2012).

68) G. Reglitz: PhD Thesis, University of Münster, Germany, (2013).

69) T.E. Hsieh and R.W. Balluffi: Acta Metall. 37 (1989) 2133.

70) G. Wilde, J. Ribbe, G. Reglitz, M. Wegner, H. Rösner, Y. Estrin, M.J. Zehetbauer, D. Setman and S.V. Divinski: Adv. Eng. Mater. 12 (2010) 758-764.

71) S.V. Divinski, G. Reglitz and G. Wilde: Acta Mater. 58 (2010) 386395.

72) D. Prokoshkina, V. Esin, G. Wilde and S.V. Divinski: Acta Mater. 61 (2013) 5188-5197.

73) G. Reglitz, B. Oberdorfer, N. Fleischmann, J.A. Kotzurek, S.V. Divinski, W. Sprengel, G. Wilde and R. Würschum: Acta Mater. 103 (2016) 396-406.

74) C. Herzig, Y. Mishin and S. Divinski: Metal. Mater. Trans. A 33 (2002) 765 .

75) A. Gupta, V. Kulitcki, B. Tas Kavakbasi, Y. Buranova, J. Neugebauer, G. Wilde, T. Hickel and S.V. Divinski: Phys. Rev. Materials 2 (2018) 073801

76) G. Erdélyi, W. Lojkowski, D.L. Beke, I. Gödény and F.J. Kedves: Philos. Mag. A 56 (1987) 673-680.

77) I. Kaur, Yu. Mishin and W. Gust: Fundamentals of Grain and Interphase Boundary Diffusion, (Wiley, Chichester, 1995).

78) O.K. Johnson, L. Li, M.J. Demkowicz and C.A. Schuh: J. Mater. Sci. 50 (2015) 6907-6919.

79) B.P. Uberuaga, L.J. Vernon, E. Martinez and A.F. Voter: Sci. Rep. 5 (2015) 9095

80) J. Han, V. Vitek and D.J. Srolovitz: Acta Mater. 104 (2016) 259-273.

81) D. Turnbull and R.E. Hoffman: Acta Metall. 2 (1954) 419-426.

82) P. Klugkist, A.N. Aleshin, W. Lojkowski, L.S. Shvindlerman, W. Gust and E.J. Mittemeijer: Acta Mater. 49 (2001) 2941-2949.

83) E. Budke, T. Surholt, S.I. Prokofjev, L.S. Shvindlerman and C. Herzig: Acta Mater. 47 (1999) 385-395.

84) T. Surholt, D. Molodov and C. Herzig: Acta Mater. 46 (1998) 53455355.

85) C. Minkwitz, C. Herzig, E. Rabkin and W. Gust: Acta Mater. 47 (1999) 1231-1239.

86) H. Edelhoff, S.I. Prokofjev and S.V. Divinski: Scr. Mater. 64 (2011) 374-377.

87) S.V. Divinski, H. Edelhoff and S. Prokofjev: Phys. Rev. B 85 (2012) 144104.

88) T. Frolov, S.V. Divinski, M. Asta and Y. Mishin: Phys. Rev. Lett. 110 (2013) 255502.

89) Z. Horita, D.J. Smith, M. Nemoto, R.Z. Valiev and T.G. Langdon: J. Mater. Res. 13 (1998) 446.

90) Z.B. Wang, K. Lu, G. Wilde and S.V. Divinski: Acta Mater. 58 (2010) 2376-2386.

91) M. Wegner, J. Leuthold, M. Peterlechner, D. Setman, M. Zehetbauer, R. Pippan, S.V. Divinski and G. Wilde: J. Appl. Phys. 114 (2013) 183509.

92) J. Ribbe, G. Schmitz, H. Rösner, R. Lapovock, Y. Estrin, G. Wilde and S.V. Divinski: Scr. Mater. 68 (2013) 925-928.

93) J. Ribbe, G. Schmitz, D. Gunderov, Y. Estrin, Y. Amouyal, G. Wilde and S.V. Divinski: Acta Mater. 61 (2013) 5477-5486.

94) Y. Qi, A. Kosinova, A.R. Kilmametov, B.B. Straumal and E. Rabkin: Mater. Charact. 145 (2018) 1-9. 